\title{
A New Modulated Finite Control Set-Model Predictive Control of Quasi-Z-Source Inverter for PMSM Drives
}

\author{
Abdelsalam A. Ahmed 1,*, Abualkasim Bakeer 2,3 ${ }^{\mathbb{D}}$, Hassan Haes Alhelou 4,5,*, Pierluigi Siano $6,7, * \mathbb{D}$ \\ and Mahmoud A. Mossa ${ }^{8,9}$ (D)
}

Citation: Ahmed, A.A.; Bakeer, A.; Alhelou, H.H.; Siano, P.; Mossa, M.A. A New Modulated Finite Control Set-Model Predictive Control of Quasi-Z-Source Inverter for PMSM Drives. Electronics 2021, 10, 2814. https: / / doi.org/10.3390/ electronics10222814

Academic Editors: Dongkyun Kim, Qinghe Du, Mehdi Sookhak, Lei Shu, Nurul I. Sarkar, Jemal H. Abawajy and Francisco Falcone

Received: 1 November 2021 Accepted: 15 November 2021 Published: 16 November 2021

Publisher's Note: MDPI stays neutral with regard to jurisdictional claims in published maps and institutional affiliations.

Copyright: (c) 2021 by the authors. Licensee MDPI, Basel, Switzerland. This article is an open access article distributed under the terms and conditions of the Creative Commons Attribution (CC BY) license (https:// creativecommons.org/licenses/by/ $4.0 /)$.
1 Laboratory of EV/HEV Technology, Department of Electrical Power and Machines Engineering, Faculty of Engineering, Tanta University, Tanta 31527, Egypt

2 Electrical Engineering Department, Faculty of Engineering, Aswan University, Aswan 81542, Egypt; abbake@taltech.ee

3 Electrical Power Engineering and Mechatronics Department, Tallinn University of Technology, 12616 Tallinn, Estonia

4 Department of Electrical Power Engineering, Faculty of Mechanical and Electrical Engineering, Tishreen University, Lattakia 2230, Syria

5 School of Engineering, RMIT University, 124 La Trobe St., Melbourne, VIC 3000, Australia

6 Department of Management \& Innovation Systems, University of Salerno, 84084 Fisciano, Italy

7 Department of Electrical and Electronic Engineering Science, University of Johannesburg, Johannesburg 2024, South Africa

8 Electrical Engineering Department, Faculty of Engineering, Minia University, Minia 61111, Egypt; mahmoud_a_mossa@mu.edu.eg

9 Department of Industrial Engineering, University of Padova, Via Gradenigo 6/a, 35131 Padova, Italy

* Correspondence: abdelsalam.abdelsalam@f-eng.tanta.edu.eg (A.A.A.); hassan.haes.alhelou@rmit.edu.au (H.H.A.); psiano@unisa.it (P.S.)

Abstract: In this paper, a new modulated finite control set-model predictive control (FCS-MPC) methodology is proposed for a quasi-Z-source inverter (qZSI). The application of the qZSI in this paper is to drive the permanent magnet synchronous machine (PMSM). The proposed methodology calculates the optimal duration time (ODT) for the candidate vector from the switching patterns of the inverter after it is selected from the FCS-MPC algorithm. The control objective of the FCS-MPC are the three-phase currents of PMSM, when the motor speed is below or equal to the base speed. While at a speed beyond the based speed, the inductor current and capacitor voltage of the qZS network are added as control objectives. For each candidate optimal vector, the optimal time, which is a part of the sampling interval, is determined based on minimizing the ripples of the control objectives using a quadratic cost function. Then, the optimal vector is applied only to the inverter switches during the calculated ODT at the start of the sampling interval, while the zero vector is applied during the remaining part of the sampling interval. To reduce the calculation burden, the zero-state is excluded from the possible states of the inverter, and the sub-cost function definition is used for the inductor current regulation. The proposed modulated FCS-MPC is compared with the unmodulated FCS-MPC at the same parameters to handle a fair comparison. The simulation results based on the MATLAB/Simulink@ software shows the superiority of the proposed algorithm compared to the unmodulated FCS-MPC in terms of a lower ripple in the inductor current and capacitor voltage, and a lower THD for the PMSM currents.

Keywords: modulated finite control set-model predictive control; quasi-Z-source inverter; permanent magnet synchronous motor; optimal duration

\section{Introduction}

The quasi-Z-source inverter (qZSI) has been introduced in research as an advanced topology from the primary one, ZSI, by reserving the same number of components [1,2]. The qZSI minimizes the capacitor voltage stress, makes the drawn current from the supply 
continuous, and has the same voltage conversion ratio as the basic ZSI [3]. This family of ZSI engages both the buck and boost functionality within a single unit without needing more elements.

The integration of qZSI in drive applications has been reported in several publications [4-6]. The reason for this is that it is more capable of adjusting the DC-link voltage to the wide-range variations in speed compared to the conventional voltage source inverter (VSI). Typically, the field weakening control (FWC) method is applied when the speed command is beyond the rated speed of the machine with the VSI. However, the current of the machine is increased with the FWC, and therefore the efficiency will deteriorate at a higher speed [7]. Thus, the ZSI family expands the flexibility of using the drive system like an electric vehicle that is significantly growing every year around the world.

A permanent magnet synchronous machine (PMSM) has a simple structure, a compact size, and a high-power density. Moreover, in PMSM, the slip ring is missing, and the rotor does not use any winding to generate the magnetic flux, as it results from the magnetic poles on the rotor and the stator windings. These features reduce conduction losses and improve the overall efficiency of the PMSM. To control the PMSM speed, several techniques are developed, such as conventional techniques [8,9] and model predictive control (MPC) [10,11]. The latter demonstrates a superior performance during the transient and steady state, where the actuation of the switches of the inverter with the MPC is done using a future vision based on the current values of the control objectives. The priority of each control goal inside the objective function is managed by adjusting its corresponding weighting factor [12].

A finite control set-MPC (FCS-MPC) is a class in the MPC category, which depends on the finite number of switching states of the topology switches. It has been applied for qZSI to drive the PMSM in [11], and the results have shown that qZSI can derive the PMSM below and above the base speed without the need to apply FWC. In [13], the presented methodology used a PI loop to regulate the capacitor voltage and to generate the reference value of the inductor current. In addition, the sub cost function definition proposed in [14] is employed to improve the calculation burden. Although the technique presented in [14] offers a more accurate value for the reference current than the one obtained using the estimation way, it sacrifices the overall response as an extra control loop based on the conventional PI. Another drawback here is that the capacitor voltage is regulated also inside the cost function, and this is considered more effort. Predictive torque control (PTC) has been applied to the induction motor with the bidirectional qZSI (BqZSI) in [15]. The optimization law includes the torque and flux from the machine side and the capacitor voltage in the BqZS network. While in [16], the optimization law regulates only the machine side objectives of the torque and flux.

The methodology to apply the optimal vector from the FCS-MPC algorithm during all the sampling interval increases the ripples in the control objectives, especially when the sampling rate is high in the case of an unpowerful implementation platform. Several studies have reviewed the variable duty optimization techniques and have identified the research gaps in the field [17-19]. In [17], the duty-cycle is calculated based on the torque and flux difference parameters, and two vectors have been applied inside one sampling interval for the PMSM with VSI, whereas the duty-cycle of the shoot-through vector is calculated only based on the ripple of the inductor current, as in [18]. In [19], the authors presented the modulated MPC (M-MPC) to calculate the duty-cycle of the shoot-through state to control the inductor current in the ZSI-based PMSM drive. The presented algorithm does not employ any weighting factor inside the cost function, and the ZSI can operate at a fixed switching frequency. In [20], the authors proposed an algorithm to minimize the torque ripple with a similar topology, called modified qZSI. The introduced algorithm calculated the time of each applied voltage vector like the conventional space vector modulation.

Recent promising control techniques, based on a finite-time command filter, have been researched to minimize the tracking errors in the non-linear systems [21-25]. The 
command filtered adaptive output feedback control is presented in [21] for minimizing the tracking error. The control method is verified by comparing it to the tracking error of the adaptive output feedback control. In [22], an adaptive finite-time command filtering control, based on a neural network, was proposed for switched nonlinear systems. A good tracking performance was obtained under both the arbitrary switchings and the backlashlike hysteresis input. In [23], a finite-time adaptive fuzzy tracking control was presented for multi-input multi-output nonlinear systems with input saturation. In [24], an improved finite-time tracking control command filter was designed to ensure that the output of the filter can approximate the derivatives of virtual signals more quickly, suppress chattering, and relax the input signal limit of the Levant differentiator. Although these references have presented promising control methodologies with some stability analysis, their validity can be reliable when applied to electrical drive and motor control systems. In [25], the inductor current, capacitor voltage, and output current of the qZSI were controlled by a logical operation-based MPC in two separate cascaded stages, i.e., control logic and judgment logic. Therefore, the weighting factors are eliminated. However, this method is not yet applied to the PMSMs or IMs.

Unmodulated FCE-MPC is the current popular MPC for the PMSM driven by qZSI. In this method, the optimum selected voltage vector is applied during the whole sampling period, as in [26]. In this way, the ripples in the inductor current and capacitor voltage of the qZSI become visibly high. This paper proposes a methodology for calculating the optimal duration time (ODT) to reduce the ripples in the qZSI inductor current and capacitor voltage and the PMSM currents. The optimal duration for the active and shoot-through vectors is calculated based on the proposed criteria within a quadratic cost function. In the remaining part of the sampling interval of these vectors, the zero-state vector is applied to the qZSI switches. Using the zero vector after the shoot-through vector prevents the inductor current to continue charging until the sampling interval ends, while for the PMSM currents, optimizing the time to apply the active vector minimizes the total harmonics distortion (THD). This is beneficial to the high sampling rate in case of using the low-cost digital platform in the implementation. Furthermore, the calculation burdens are reduced by excluding the zero vector from the calculations inside the FCS-MPC algorithm. The validation of the effect of ODT on the inductor current, capacitor voltage, and machine's current is presented in detail. The algorithm covers the whole operational speed range of PMSM.

In general, the paper contributions can be listed as:

- Proposing a new model predictive control methodology to calculate the optimal duration time (ODT) for the optimized voltage vector that results from the FCS-MPC algorithm.

- $\quad$ The criteria to calculate the ODT are based on minimizing the ripples in the qZSI inductor current, the qZSI capacitor voltage, and the PMSM currents using a quadratic cost function.

- Deriving the optimal duration time interval with mathematical analysis for the proposed methodology.

- The zero-vector is excluded from the calculations in the main loop to avoid computational burdens.

- Simulating the proposed modulated FCS-MPC using the MATLAB/Simulink software.

- Comparing the proposed controller with the conventional algorithm in the literature of FCS-MPC with qZSI.

- The proposed algorithm minimizes the ripple of the inductor current and capacitor voltage of the qZSI, and the dynamic performance of the controlled PMSM is achieved.

- A lower THD for the PSMS currents compared to that based on the conventional FCS-MPC of qZSI has been achieved.

The remainder of this paper starts with Section 2, which describes the discrete model of the qZSI and PMSM. Section 3 demonstrates the proposed modulated FCS-MPC algorithm 
in detail, while Section 4 shows the simulation results and Section 5 reports the paper's conclusions.

\section{System Description and Modeling}

The PMSM terminals are connected to the three-phase inverter fed from the DC-link voltage of the qZS network, as shown in Figure 1. The inverter has three legs with two switches each, and each switch has two states, either ON or OFF (ON refers to binary 1, while OFF refers to binary 0 ). Therefore, the total number of the possible switching states of the inverter is eight, i.e., 23. These states can be classified into three groups, which are: zero-state (V1), active states (V2:V7), and shoot-through (ST) state (V8). For PMSM, the shoot-through state and the zero state, which could be called the null state, have the same effect on the machine currents and speed, as a zero voltage is applied to the stator in both states. Table 1 summarizes the space vectors of the output voltage during the possible switching states of qZSI. In the remaining part of the paper, $V_{d c}$ refers to the DC-link voltage before the inverter stage.

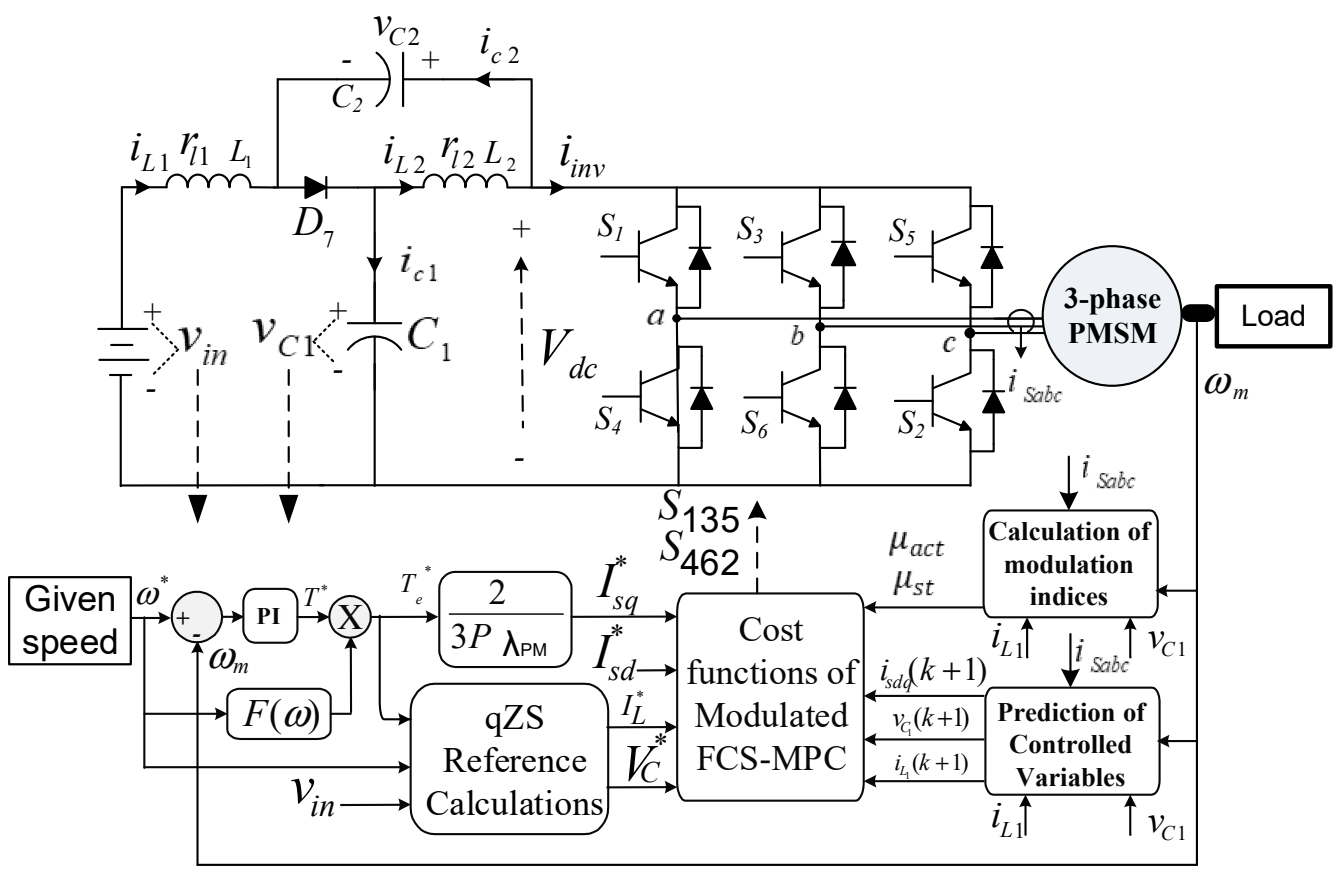

Figure 1. Modulated FCS-MPC scheme of PMSM with qZSI.

Table 1. Possible switching states of qZSI.

\begin{tabular}{|c|c|c|c|c|c|c|c|c|}
\hline & State & Vector & $S_{1}$ & $S_{3}$ & $S_{5}$ & $S_{4}$ & $S_{6}$ & $S_{2}$ \\
\hline \multirow{7}{*}{ NST } & Zero-state & V1 & OFF & OFF & OFF & $\mathrm{ON}$ & ON & $\mathrm{ON}$ \\
\hline & \multirow{6}{*}{ Active states } & V2 & ON & OFF & OFF & OFF & ON & $\mathrm{ON}$ \\
\hline & & V3 & $\mathrm{ON}$ & $\mathrm{ON}$ & OFF & OFF & OFF & $\mathrm{ON}$ \\
\hline & & $\mathrm{V} 4$ & OFF & $\mathrm{ON}$ & OFF & $\mathrm{ON}$ & OFF & $\mathrm{ON}$ \\
\hline & & V5 & OFF & $\mathrm{ON}$ & $\mathrm{ON}$ & ON & OFF & OFF \\
\hline & & V6 & OFF & OFF & $\mathrm{ON}$ & $\mathrm{ON}$ & $\mathrm{ON}$ & OFF \\
\hline & & V7 & $\mathrm{ON}$ & OFF & ON & OFF & $\mathrm{ON}$ & OFF \\
\hline ST & Shoot-through state & V8 & $\mathrm{ON}$ & ON & $\mathrm{ON}$ & ON & $\mathrm{ON}$ & $\mathrm{ON}$ \\
\hline
\end{tabular}




\subsection{Mathematical Model of the PMSM Part}

The type of PMSM in this study is surface-mounted, so the direct and quadrature inductances of the machine are equivalent, i.e., $L_{d}=L_{q}$. The three-phase currents of the stator are converted into the rotational dq-coordinate using the Park transformation. These current components represent the input state-variables vector of the PMSM, i.e., $x=\left[\begin{array}{cc}i_{s d} & i_{s q}\end{array}\right]^{T}$, where $T$ is the matrix transpose. The input or control vector is the stator voltage in the dq frame, i.e., $v=\left[\begin{array}{ll}v_{s d} & v_{s q}\end{array}\right]^{T}$. Accordingly, the continuous state-space model of the PMSM can be expressed as

$$
\frac{d}{d t}\left[\begin{array}{c}
i_{s d}(t) \\
i_{s q}(t)
\end{array}\right]=\left[\begin{array}{ccc}
-\frac{R_{s}}{L_{d}} & \frac{L_{q}}{L_{d}} \omega(t) & 0 \\
-\frac{L_{d}}{L_{q}} \omega(t) & -\frac{R}{L_{q}} & -\frac{1}{L_{q}} \lambda_{P M}
\end{array}\right]\left[\begin{array}{c}
i_{s d}(t) \\
i_{s q}(t) \\
\omega(t)
\end{array}\right]+\left[\begin{array}{cc}
\frac{1}{L_{d}} & 0 \\
0 & \frac{1}{L_{q}}
\end{array}\right]\left[\begin{array}{c}
v_{s d}(t) \\
v_{s q}(t)
\end{array}\right]
$$

where $R_{S}$ is the phase resistance and $\omega(t)$ is the electrical angular speed of the PMSM. Besides, the voltages $v_{s d}(t)$ and $v_{s q}(t)$ can be evaluated from the switching state of the inverter and the DC-link voltage as

$$
\left[\begin{array}{c}
v_{s d}(t) \\
v_{s q}(t)
\end{array}\right]=\frac{2 V_{d c}}{3}\left[\begin{array}{ccc}
\cos (\theta) & \cos \left(\theta-\frac{2 \pi}{3}\right) & \cos \left(\theta+\frac{2 \pi}{3}\right) \\
-\sin (\theta) & -\sin \left(\theta-\frac{2 \pi}{3}\right) & -\sin \left(\theta+\frac{2 \pi}{3}\right)
\end{array}\right]\left[\begin{array}{l}
S_{1} \\
S_{3} \\
S_{5}
\end{array}\right]
$$

where $\theta$ is the electrical angle and $\left(S_{1}, S_{3}, S_{5}\right)$ are the switching functions of the three-phase inverter.

\subsection{Mathematical Model of the qZS Part}

The configuration of the qZS network depends on the switching state of the inverter switches. The state-variables in the qZS network are the current in the inductor $L_{1}$ and the voltage across the capacitor $C_{1}$. The analysis of this part assumes that the currents in the two inductances of $L_{1}$ and $L_{2}$ are typical due to the symmetry of $L_{1}$ and $L_{2}$. Furthermore, the capacitor voltage is indirectly employed to regulate the DC-link voltage of the inverter, as it has a constant value, while the DC-link voltage is a pulsating waveform, which needs more complicated circuits to detect the actual value.

\subsubsection{Zero-State}

The zero-state is obtained through shortening the upper or the lower switches of the three legs in the inverter. The equations of inductor current and capacitor voltage will not be driven here because the discrete model of the controlled variable will not be used with this state. This state will be inserted in the remaining part of the active or shoot-through vector, as discussed below.

\subsubsection{Active States}

In this case, the diode $\mathrm{D}_{7}$ has a forward-biased state, and therefore there will be a direct connection between the input source $v_{i n}$ and the PMSM, as shown in Figure 2. According to this circuit configuration, the differential equations that describe the state-variables can be expressed as

$$
\begin{gathered}
\frac{d}{d t} i_{L 1}(t)=\frac{1}{L_{1}}\left(v_{i n}(t)-v_{C 1}(t)-r_{l 1} i_{L 1}(t)\right) \\
\frac{d}{d t} v_{C 1}(t)=\frac{1}{C_{1}}\left(i_{L_{1}}(t)-i_{\text {inv }}(t)\right)
\end{gathered}
$$

where $L_{1}$ and $C_{1}$ are the inductance and capacitance of the LC network, $r_{l 1}$ is the parasitic resistance of the inductor, $v_{i n}(t)$ is the input voltage, $v_{C 1}(t)$ is the capacitor voltage of 
$C_{1}, i_{L_{1}}(t)$ is the inductor current of $L_{1}$, and $i_{\text {inv }}(t)$ is the instantaneous dc-current drawn by the inverter during this case, that can be calculated by

$$
i_{\text {inv }}(t)=i_{a} S_{1}(i, 1)+i_{b} S_{3}(i, 2)+i_{c} S_{5}(i, 3)
$$

where $i$ is the number of the switching vector.

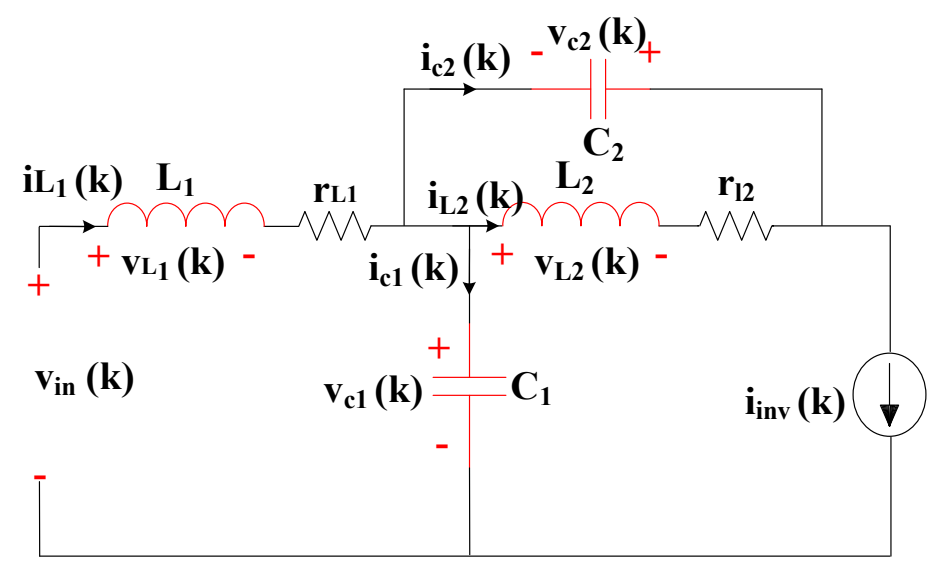

Figure 2. qZSI circuit in the active states.

\subsubsection{Shoot-Through State}

This case can be generated by shortening at least one of the three legs of the inverter. During this case, the diode $\mathrm{D}_{7}$ has a reversed-biased state, and both inductors and capacitors exchange their energy, in which case the inductors are discharging, whereas the capacitors are charging, as shown in Figure 3. The state-variable equations during this state are:

$$
\begin{gathered}
\frac{d}{d t} i_{L 1}(t)=\frac{1}{L_{1}}\left(v_{C 2}(t)+v_{i n}(t)-r_{l 1} i_{L 1}(t)\right) \\
\frac{d}{d t} v_{C 1}(t)=-\frac{1}{C_{1}} i_{L_{1}}(t)
\end{gathered}
$$

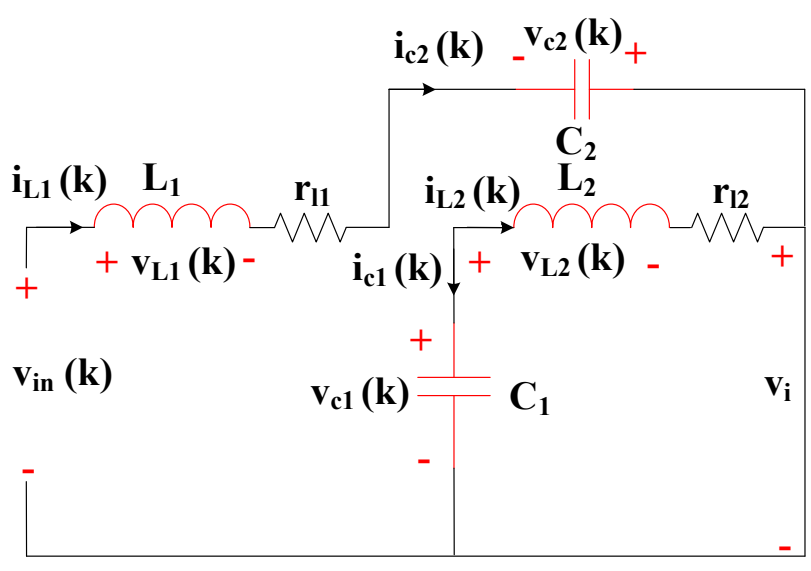

Figure 3. Equivalent circuit of qZSI in the shoot-through state.

\section{Proposed Modulated-MPC of qZSI-Based Vector Optimal Duration}

FCS-MPC selects the optimal vector from the possible vectors of the converter, and it remains applied until the next sampling interval. The main idea behind the proposed technique is to find the time to apply the optimal vector and apply the zero vector in the remaining part of the sampling interval. 


\subsection{References of Control Objectives}

The PMSM speed, $\omega_{m}$, is regulated to the reference speed, $\omega_{m}^{*}$, using a PI control loop that generates the reference of the electrical torque $T_{e}^{*}$ of the PMSM as

$$
T_{e}^{*}=\left(K_{p}+\frac{K_{i}}{S}\right)\left(\omega_{m}^{*}-\omega_{m}\right)
$$

where $K_{p}$ and $K_{i}$ are the proportional and integral gains of the PI speed controller, respectively. The load torque must be derated when the speed increases beyond the base speed, $\omega_{b}$, to avoid the overheating of the machine windings. So, the weakening factor, $F$, is defined as a function of motor speed as

$$
F\left(\omega_{m}\right)=\left\{\begin{array}{c}
\frac{\omega_{b}}{\omega_{m}} \omega_{b}<\omega_{m} \leq \omega_{\max } \\
1-\omega_{b} \leq \omega_{m} \leq \omega_{b}
\end{array}\right.
$$

To achieve the maximum torque per ampere (MTPA), where the efficiency is high, the reference current in the d-axis of the PMSM is defined as zero, i.e., $I_{s d}^{*}=0$. At this condition, the reactive power absorbed by the PMSM has the minimum value, while for the quadrature current, the reference value depends on the reference torque from the speed regulator, as:

$$
I_{s q}^{*}=\frac{2}{3 P \lambda_{P M}} F\left(\omega_{m}\right) T_{e}^{*}
$$

When the speed command is set above the base value, the qZSI operates in the boosting mode, and therefore the inductor current and capacitor voltage are controlled with the proposed modulated FCS-MPC. The reference value of the inductor current is computed based on the reference electromagnetic torque from (8) and the given reference speed as:

$$
I_{L}^{*}=\left|F\left(\omega_{m}\right) T_{e}^{*} \frac{\omega_{m}^{*}}{v_{i n}}\right|
$$

Then, the stator voltage of PMSM must be adjusted to the command speed. This can be achieved by defining the reference capacitor voltage in (12) as a function of the command speed and the input voltage.

$$
V_{C}^{*}=\left\{\begin{array}{c}
\frac{1}{2} v_{\text {in }}\left(1+1.5 *\left|\frac{\omega_{m}^{*}}{\omega_{b}}\right|\right) \omega_{b}<\left|\omega_{m}\right| \leq \omega_{\max } \\
v_{\text {in }} 0 \leq\left|\omega_{m}\right| \leq \omega_{b}
\end{array}\right.
$$

Below the base speed of the PMSM, the qZSI works in buck mode and the DC-link voltage remains nearly constant at the input voltage. While in the boost mode, its peak value is a function of the reference voltage of the capacitor and the input voltage, as in (13).

$$
V_{d c}^{*}=\left\{\begin{array}{c}
2 V_{C}^{*}-v_{\text {in }} \omega_{b}<\left|\omega_{m}\right| \leq \omega_{\max } \\
v_{\text {in }} 0 \leq\left|\omega_{m}\right| \leq \omega_{b}
\end{array}\right.
$$

The reference states could be summarized in matrix form as:

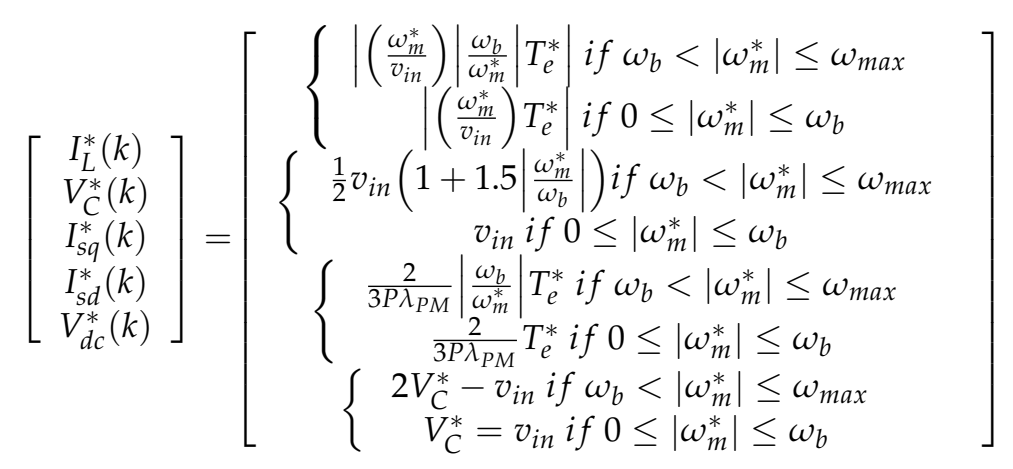




\subsection{Prediction of the Control Objectives}

The next step in the FCS-MPC algorithm is to define the discrete model of the control objectives. The trajectory of the control objectives at the different switching states of the inverter can be predicted utilizing their discrete model. The Forward Euler equation has been adopted to solve the differential equations derived in the previous section. The prediction model depends on the sampling interval, $T_{s}$. The discrete model for the PMSM current is given by

$$
\begin{gathered}
{\left[\begin{array}{c}
I_{s d}^{P}(k+1) \\
I_{s q}^{P}(k+1)
\end{array}\right]=\left[\begin{array}{cc}
\left(1-\frac{R T_{s}}{L}\right) & T_{s} \omega_{m} \\
-T_{s} \omega_{m} & \left(1-\frac{R T_{s}}{L}\right)
\end{array}\right]\left[\begin{array}{c}
I_{s d}(k) \\
I_{s q}(k)
\end{array}\right]+\left[\begin{array}{cc}
\frac{T_{s}}{L} & 0 \\
0 & \frac{T_{s}}{L}
\end{array}\right]\left[\begin{array}{c}
V_{s d}(k) \\
V_{s q}(k)
\end{array}\right]+} \\
\\
{\left[\begin{array}{c}
0 \\
-\lambda_{P M} \omega_{m} \frac{T_{s}}{L}
\end{array}\right]}
\end{gathered}
$$

where the voltage components $V_{s d q}(k)$ are the measured voltage of the stator windings at time $k$. Table 2 summarizes the discrete model of the qZS network part during only the active and shoot-through cases because the zero-state will not be employed inside the FCS-MPC loop, as discussed below. It could be noticed that the control variables have been set in terms of their own optimal modulations indices, where $\mu_{a c t}$ and $\mu_{s T}$ are the modulation indices in the active state and shoot-through state, respectively.

Table 2. Prediction of control states with modulation index.

\begin{tabular}{ccc}
\hline State & Capacitor Voltage $V_{c 1}^{P}(k+1)=$ & Inductor Current $I_{L 1}^{P}(k+1)=$ \\
\hline Active states & $V_{c 1}(k)+\frac{\mu_{a c t} T_{S}}{c_{1}}\left(i_{L 1}^{P}(k+1)-i_{\text {inv }}(k+1)\right)$ & $\frac{\mu_{a c t} T_{S}\left(v_{i n}-V_{c 1}(k)\right)+L_{1} I_{L 1}(k)}{L_{1}+R_{L 1} \mu_{a c t} T_{s}}$ \\
\hline Shoot-through state & $V_{c 1}(k)-\frac{\mu_{s} T_{S}}{c_{1}}\left(I_{L 1}^{P}(k+1)\right)$ & $\frac{\mu_{s T} T_{S} V_{C 1}(k)+L_{1} I_{L 1}(k)}{L_{1}+\mu_{s T} T_{s} R_{L 1}}$ \\
\hline
\end{tabular}

\subsection{Modulation Intervals for the qZSI-Based PMSM Drives}

The dynamic equations of the proposed modulated MPC are explained and derived in detail. Moreover, they have been compared to the conventional MPC. The shoot-through optimal duration $\left(\mu_{s T}\right)$ has been derived in detail, while the $\mu_{s T}$ in the conventional MPC is set to 1. The proposed M-MPC is mapped in a flow chart as shown in Figure 4. In this flowchart, the implementation process is described during each executing sampling interval in the following sequence:

- Initialization and measurements

- Calculations of references for qZSI and PMSM

- Prediction of currents

- Selection of the optimal voltage vector

- Calculation of optimal duty for the selected voltage vector

- Applying the selected vector within its optimal duty to the inverter, while the zero vector is applied for the rest time 


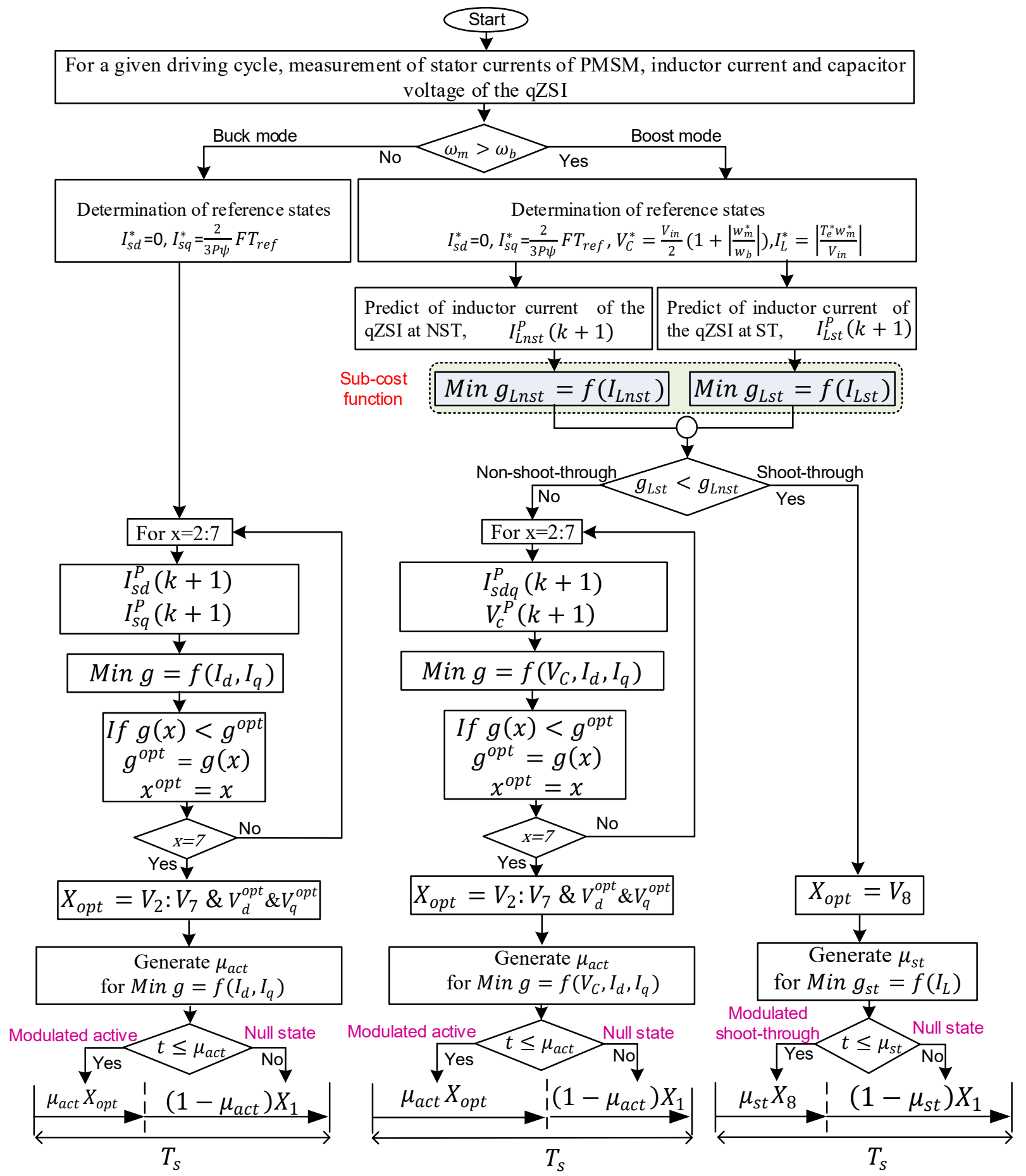

Figure 4. Flowchart of the proposed modulated FCS-MPC algorithm for qZSI applied to PMSM drives.

\subsubsection{Cost Functions at a Speed beyond Base Speed}

For minimizing the calculation burden, two cost functions are tested in parallel for the ST and NST states to track the reference inductor current. The prediction current of the qZS inductor has the same value in all the six active vectors. The cost functions with the ST and NST intervals are described in (16) and (17), respectively. The quadratic cost functions are used to increase accuracy and sensitivity. The results for low switching frequency can be improved by considering a squared error for the control variables of the cost function.

$$
g_{s t}=\left(I_{L}^{*}(k)-I_{L 1 s t}^{P}(k+1)\right)^{2}
$$




$$
g_{n s t}=\left(I_{L}^{*}(k)-I_{\text {L1nst }}^{P}(k+1)\right)^{2}
$$

The cost functions for the two cases are calculated to decide which state should be applied instead of testing all the eight switching states. This methodology is known as a sub-cost function definition, tested before executing the main cost function, whereas the capacitor voltage has different values with all the eight states. Therefore, it is better to employ the inductor current.

Once the shoot-through state is selected, the vector and its ODT $\left(\mu_{s T} X_{8}\right)$ is applied at the beginning of the interval to minimize the inductor current ripple, whereas the zero vector is applied in the remaining time, i.e., $\left(1-\mu_{S T}\right) \mathrm{X}_{1}$. In the same way, when the nonshoot-through mode is selected, the optimum voltage vector is chosen for tracking the current components of the PMSM and the capacitor voltage, as in (18).

$$
g=K_{d}\left(I_{s d}^{*}-I_{s d}^{P}(k+1)\right)^{2}+K_{q}\left(I_{s q}^{*}-I_{s q}^{P}(k+1)\right)^{2}+K_{c}\left(V_{C}^{*}-V_{c 1}^{P}(k+1)\right)^{2}
$$

where $K_{d}, K_{q}$, and $K_{c}$ are the weighting factors for the different terms of the cost function. The candidate active vector $X_{o p t}$ is the selected vector from $X_{2}: X_{7}$ and is applied during the time $\mu_{\text {act }} T_{s}$. In the remaining time, $T_{s}$, the zero voltage is applied $\left(1-\mu_{\text {act }}\right) T_{s}$.

\subsubsection{Shoot-Through Optimal Duration $\left(\mu_{s T}\right)$ beyond the Base Speed}

The shoot-through state is exploited to boost the input voltage to the desired value based on the command speed of the PMSM. Substituting from Table 2 by the predicted current during the shoot-through state in the cost function of (16), the latter could be rewritten as:

$$
g_{s t}=\left(I_{L}^{*}(k)-\frac{\left(A_{1} \mu_{s T}+A_{2}\right)}{\left(A_{4} \mu_{s T}+A_{3}\right)}\right)^{2}
$$

where the coefficients can be defined in matrix form as:

$$
\left[\begin{array}{c}
A_{1} \\
A_{2} \\
A_{3} \\
A_{4}
\end{array}\right]=\left[\begin{array}{ccc}
0 & T_{s} & 0 \\
L_{i n} & 0 & 0 \\
0 & 0 & L_{i n} \\
0 & 0 & T_{s} R_{\text {in }}
\end{array}\right]\left[\begin{array}{c}
I_{L 1}(k) \\
V_{C 1}(k) \\
1
\end{array}\right]
$$

The condition for minimizing the ripple in the inductor current, $\frac{d g_{s t}}{d \mu_{s T}}=0$, can be defined as:

$$
-2\left(\frac{I_{L_{r e f}}\left(A_{4} \mu_{s T}+A_{3}\right)-\left(A_{1} \mu_{s T}+A_{2}\right)}{\left(A_{4} \mu_{s T}+A_{3}\right)}\right) *\left(\frac{A_{1}\left(A_{4} \mu_{s T}+A_{3}\right)-A_{4}\left(A_{1} \mu_{s T}+A_{2}\right)}{\left(A_{4} \mu_{s T}+A_{3}\right)^{2}}\right)=0
$$

Substituting from (14) into (20) by the reference variables, the modulation interval during the shoot-through operation could be defined through the following derivation steps:

$$
\begin{aligned}
& \left(I_{L_{r e f}}\left(A_{4} \mu_{s T}+A_{3}\right)-\left(A_{1} \mu_{s T}+A_{2}\right)\right) *\left(A_{1}\left(A_{4} \mu_{s T}+A_{3}\right)-A_{4}\left(A_{1} \mu_{s T}+A_{2}\right)\right)=0 \\
& I_{L_{r e f}} A_{1}\left(A_{4} \mu_{s T}+A_{3}\right)^{2}-I_{L_{r e f}} A_{4}\left(A_{4} \mu_{s T}+A_{3}\right) *\left(A_{1} \mu_{s T}+A_{2}\right)-A_{1}\left(A_{4} \mu_{s T}+A_{3}\right)\left(A_{1} \mu_{s T}+A_{2}\right)+A_{4}\left(A_{1} \mu_{s T}+A_{2}\right)^{2}=0 \\
& I_{L_{r e f}} A_{1}\left(A_{4}^{2} \mu_{s T}^{2}+2 A_{3} A_{4} \mu_{s T}+A_{3}^{2}\right)-I_{L_{r e f}} A_{4}\left(A_{1} A_{4} \mu_{s T}^{2}+A_{3} A_{1} \mu_{s T}+A_{4} A_{2} \mu_{s T}+A_{2} A_{3}\right)- \\
& A_{1}\left(A_{1} A_{4} \mu_{s T}^{2}+A_{2} A_{3}+A_{3} A_{1} \mu_{s T}+A_{4} A_{2} \mu_{s T}\right)+A_{4}\left(A_{1}^{2} \mu_{s T}^{2}+2 A_{1} A_{2} \mu_{s T}+A_{2}^{2}\right)=0 \\
& I_{L_{r e f}} A_{1} A_{4}^{2} \mu_{s T}^{2}+2 I_{L_{r e f}} A_{1} A_{3} A_{4} \mu_{s T}+I_{L_{r e f}} A_{1} A_{3}^{2}-I_{L_{r e f}} A_{4}^{2} A_{1} \mu_{s T}{ }^{2}-I_{L_{r e f}} A_{4} A_{3} A_{1} \mu_{s T}- \\
& I_{L_{r e f}} A_{4}^{2} A_{2} \mu_{s T}-I_{L_{r e f}} A_{4} A_{2} A_{3}-A_{1}^{2} A_{4} \mu_{s T}{ }^{2}-A_{1} A_{2} A_{3}-A_{3} A_{1}^{2} \mu_{s T}- \\
& A_{1} A_{4} A_{2} \mu_{s T}+A_{4} A_{1}{ }^{2} \mu_{s T}{ }^{2}+2 A_{1} A_{2} A_{4} \mu_{s T}+A_{4} A_{2}{ }^{2}=0
\end{aligned}
$$




$$
\begin{gathered}
\mu_{s T}\left(2 I_{L_{r e f}} A_{1} A_{3} A_{4}-I_{L_{r e f}} A_{4} A_{3} A_{1}-I_{L_{r e f}} A_{4}^{2} A_{2}-A_{3} A_{1}^{2}-A_{1} A_{4} A_{2}+2 A_{1} A_{2} A_{4}\right)+ \\
I_{L_{r e f}} A_{1} A_{3}^{2}-I_{L_{r e f}} A_{4} A_{2} A_{3}-A_{1} A_{2} A_{3}+A_{4} A_{2}^{2}=0
\end{gathered}
$$

Then, the modulation interval during the shoot-through operation could be determined by

$$
\mu_{s T}=\frac{\left(A_{2} A_{3} A_{4}-A_{1} A_{3}^{2}\right) I_{L}^{*}(k)+A_{1} A_{2} A_{3}-A_{4} A_{2}^{2}}{\left(A_{1} A_{3} A_{4}-A_{2} A_{4}^{2}\right) I_{L}^{*}(k)+A_{1} A_{2} A_{4}-A_{3} A_{1}^{2}}
$$

The saturation limit of $\mu_{s T}$ is set based on the minimum value at zero and maximum value at one. Then, the shoot-through vector and its ODT $\left(\mu_{s T} \mathrm{X}_{8}\right)$ are applied at the beginning of the interval, whereas the zero voltage is applied in the remaining time, i.e., $\left(1-\mu_{s T}\right) \mathrm{X}_{1}$, as depicted on the right side of the flowchart in Figure 4.

\subsubsection{Active-State Optimal Duration $\left(\mu_{a c t}\right)$ beyond the Base Speed}

If the NST state is selected, from the sub-cost function stage, the cost function for PMSM drives involves the stator currents of the machine and the capacitor voltage of the qZSI, as in (18). From the reference states in (14) and the predicted variables defined in Table 2, the cost function could be rewritten as:

$$
g=K_{d}\left(A_{1}+A_{2} \mu_{a c t}-A_{3} \mu_{a c t}-A_{4} \mu_{a c t}\right)^{2}+K_{q}\left(B_{1}+B_{2} \mu_{a c t}+B_{3} \mu_{a c t}-B_{4} \mu_{a c t}+B_{5} \mu_{a c t}\right)^{2}+K_{c}\left(C_{1}-C_{2} \mu_{a c t}\right)^{2}
$$

Let $A_{7}=A_{2}-A_{3}-A_{4}$ and $B_{7}=B_{2}+B_{3}-B_{4}+B_{5}$. For simplicity, the cost function could be rewritten as

$$
g=K_{d}\left(A_{1}+A_{7} \mu_{a c t}\right)^{2}+K_{q}\left(B_{1}+B_{7} \mu_{a c t}\right)^{2}+K_{c}\left(C_{1}-C_{2} \mu_{a c t}\right)^{2}
$$

where the coefficients of the cost function of (28) are abbreviated in matrix form as:

$$
\left[\begin{array}{l}
A_{1} \\
A_{2} \\
A_{3} \\
A_{4}
\end{array}\right]=\left[\begin{array}{c}
I_{s d}^{*}-I_{s d} \\
\frac{R_{s} T_{s}}{L_{s}} I_{s d} \\
\omega_{m} T_{s} I_{s q} \\
\frac{V_{s d} T_{s}}{L_{s}}
\end{array}\right],\left[\begin{array}{c}
B_{1} \\
B_{2} \\
B_{3} \\
B_{4} \\
B_{5}
\end{array}\right]=\left[\begin{array}{c}
I_{s q}^{*}-I_{s q} \\
\frac{R_{s} T_{s}}{L_{s}} I_{s q} \\
\omega_{m} T_{s} I_{s d} \\
\frac{V_{s q} T_{s}}{L_{s}} \\
\frac{\lambda_{P M} \omega_{m} T_{s}}{L_{s}}
\end{array}\right] \text {, and }\left[\begin{array}{c}
C_{1} \\
C_{2} \\
C_{3} \\
C_{4}
\end{array}\right]=\left[\begin{array}{c}
V_{C}^{*}-V_{c 1} \\
\frac{T_{s}}{C} I_{L 1}-i_{\text {inv }}\left(x_{o p t}\right) \\
0 \\
0
\end{array}\right]
$$

For minimizing the errors in the control variables, $\frac{d g}{d \mu_{a c t}}=0$ :

$$
2 A_{7} K_{d}\left(A_{1}+A_{7} \mu_{a c t}\right)+2 B_{7} K_{q}\left(B_{1}+B_{7} \mu_{a c t}\right)-2 C_{2} K_{c}\left(C_{1}-C_{2} \mu_{a c t}\right)=0 .
$$

With intensive integration, (30) could be set as

$$
A_{8}+A_{9} \mu_{a c t}+B_{8}+B_{9} \mu_{a c t}-C_{8}+C_{9} \mu_{a c t}=0 .
$$

The inverter current at the optimally selected vector is given as

$$
i_{i n v}\left(x_{o p t}\right)=S\left(x_{o p t}, 1\right) i_{a}+S\left(x_{o p t}, 2\right) i_{b}+S\left(x_{o p t}, 3\right) i_{c}
$$

With the consideration of the inverter current as in (32), (31) gives

$$
\mu_{a c t}=\frac{-A_{8}-B_{8}+C_{8}}{A_{9}+B_{9}+C_{9}}
$$

where the coefficients of (33) are defined as:

$$
A_{8}=2 A_{7} K_{d} A_{1}, A_{9}=2 A_{7}^{2} K_{d}, B_{8}=2 B_{7} K_{q} B_{1}, B_{9}=2 B_{7}^{2} K_{q}, C_{8}=2 C_{2} K_{c} C_{1}, C_{9}=2 C_{2}^{2} K_{c}
$$




\subsubsection{Cost Function and Modulation below the Base Speed}

Below the base speed, qZSI works in the buck mode as the conventional VSI. Therefore, no shoot-through vector is needed, so the duty of the shoot-through is zero, while the active duty-cycle can be simply obtained by setting $K_{c}=0$ in (18) and these yields:

$$
g=K_{d}\left(I_{s d}^{*}-I_{s d}^{P}(k+1)\right)^{2}+K_{q}\left(I_{s q}^{*}-I_{s q}^{P}(k+1)\right)^{2}
$$

For minimizing the ripple of the PMSM currents, $\frac{d g}{d \mu_{a c t}}=0$. After intensive abbreviations and substitutions, the optimal duration for the active state can be defined by

$$
\mu_{a c t}=\frac{-A_{8}-B_{8}}{A_{9}+B_{9}}
$$

In addition, (35) could be derived directly from (33) when the variables of $C_{1}$ and $C_{2}$ in (29) are set as zero. The saturation limit of $\mu_{\text {act }}$ is set based on the minimum value at zero and on the maximum value at one. Then, the selected active vector and its ODT $\left(\mu_{a c t} \mathrm{X}_{\text {opt }}\right)$ are applied at the beginning of the interval, whereas the zero voltage is applied in the remaining time, i.e., $\left(1-\mu_{a c t}\right) \mathrm{X}_{1}$, as depicted in the middle and left parts of the flowchart in Figure 4.

\section{Simulation Results and Discussion}

To investigate the performance of the proposed M-MPC for the qZSI-based PMSM drives, a MATLAB/Simulink ${ }^{\circledR}$ model has been developed to simulate the proposed technique. The solver of the MATLAB/Simulink ${ }^{\circledR}$ is set to carry the simulation with a fixed step size of $1 \mu \mathrm{s}$, while the main algorithm of FCS-MPC is executed at every sampling interval. The system parameters for both the qZSI and PMSM sides are listed in Table 3. Simulation results are presented in this arrangement to verify the effect of the proposed modulated FCS-MPC over the conventional MPC on the performance of PMSM driven by qZSI as follows: (1) the dynamic performance of the PMSM and Qzsi sides has been simulated and analyzed for both modulated and unmodulated FCS-MPCs, (2) control variables (i.e., control signals and the optimal switching vector with modulated and unmodulated FCS-MPCs) have been shown, (3) small-time scale figures are depicted for describing the steady-state performance of the modulated and unmodulated FCS-MPCs, (4) the total harmonic distortion (THD) of the phase current was established to ensure the superiority of the modulated MPC over the unmodulated one, and finally (5) comparisons are performed in forward and reverse directions, and below and above the base speed.

The PI regulator of the PMSM has been tuned with a try-and-error methodology to minimize the overshoot during the transient and the steady-state error with the reference speed. Moreover, the weighting factors are determined for balancing the different terms in the designed cost function. The sub cost function is used to reduce the calculation burdens and simplify the main cost function design. According to the desired rated and maximum speeds (3000 and $5000 \mathrm{rpm}$ ) and refereeing to (14), the reference variables at steady state are set in (36).

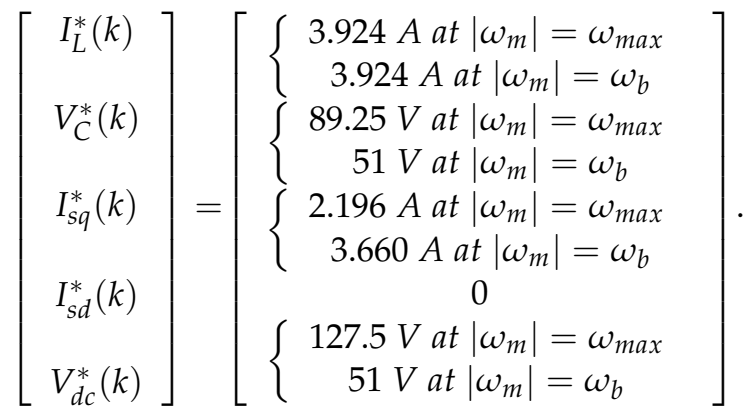


Table 3. Simulation parameters and variables.

\begin{tabular}{|c|c|c|}
\hline Specification & Unit & Value \\
\hline \multicolumn{3}{|c|}{ PMSM Parameters } \\
\hline Rated power & $\mathrm{W}$ & 200 \\
\hline Input DC voltage & $\mathrm{V}$ & 51 \\
\hline Rated/Max. speeds & $\mathrm{rpm}$ & $3000 / 5000$ \\
\hline Rated/Max. torque & $\mathrm{Nm}$ & $0.637 / 1.9$ \\
\hline Standstill current & A & 7.5 \\
\hline Pole pairs & - & 4 \\
\hline Rotor moment of inertia & $\mathrm{Kg} \cdot \mathrm{m}^{2}$ & 0.0000189 \\
\hline Friction coefficient & N.m.s/rad & 0.00001 \\
\hline Stator resistance & $\Omega$ & 0.33 \\
\hline Inductance (Ld = Lq) & $\mathrm{mH}$ & 0.9 \\
\hline Flux linkage & Web & 0.0145 \\
\hline \multicolumn{3}{|c|}{ qZSI and Control Variables } \\
\hline Sample time, $T_{S}$ & $\mu \mathrm{s}$ & 20 \\
\hline qZS inductance, $L_{1}=L_{2}$ & $\mu \mathrm{H}$ & 750 \\
\hline qZS capacitance, $C_{1}=C_{2}$ & $\mu \mathrm{F}$ & 440 \\
\hline ESR of qZS inductors, $r_{L 1}=r_{L 2}$ & $\mathrm{~m} \Omega$ & 100 \\
\hline PI speed controller gains & \multicolumn{2}{|c|}{$K_{p}=0.005 \& K_{i}=0.03$} \\
\hline Weighting factors & \multicolumn{2}{|c|}{$\lambda_{d}=1 \& \lambda_{q}=2 \& \lambda_{c}=7.5$} \\
\hline
\end{tabular}

\subsection{Dynamic Performance of the PMSM Side}

The simulation results, under the rated and maximum conditions with the proposed M-MPC and with the unmodulated MPC, are shown in Figures 5 and 6, respectively. The speed is first referenced at $3000 \mathrm{rpm}$ and then at $5000 \mathrm{rpm}$ at a load torque of $0.637 \mathrm{Nm}$, with a maximum available torque of $1.9 \mathrm{Nm}$. It is observed that the motor speed matches its reference in both M-MPC and the conventional MPC in forward and reverse directions.

The PMSM is first loaded with its rate of $0.637 \mathrm{Nm}$, and then the load is decreased such that a constant power operation is guaranteed when the speed exceeds the base value. The stator phase-current of the PMSM is limited up to $15 \mathrm{~A}$ during the speed change instant when the developed electrical torque from the speed regulator is less than the maximum of $1.9 \mathrm{Nm}$. Moreover, in both techniques, the d-axis current always equals zero during the speed variation. 

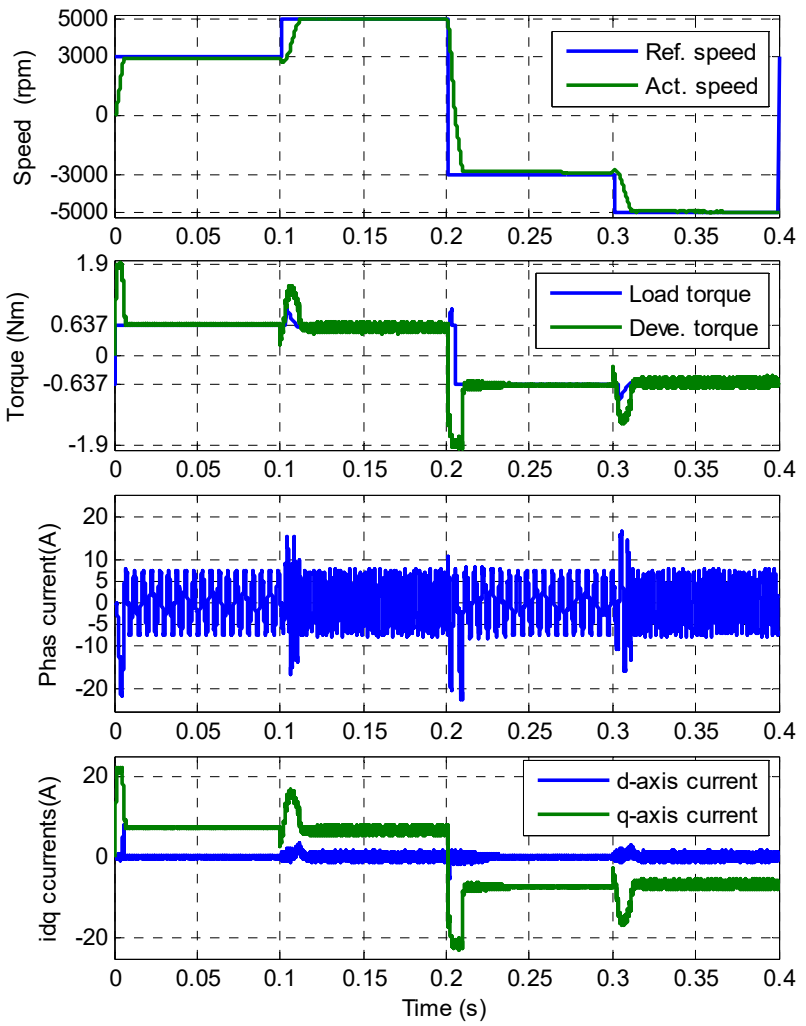

Figure 5. The dynamic performance of the PMSM side with modulated FCS-MPC. From top to bottom: reference and motor speeds, load and developed torques, phase current, and dq currents.
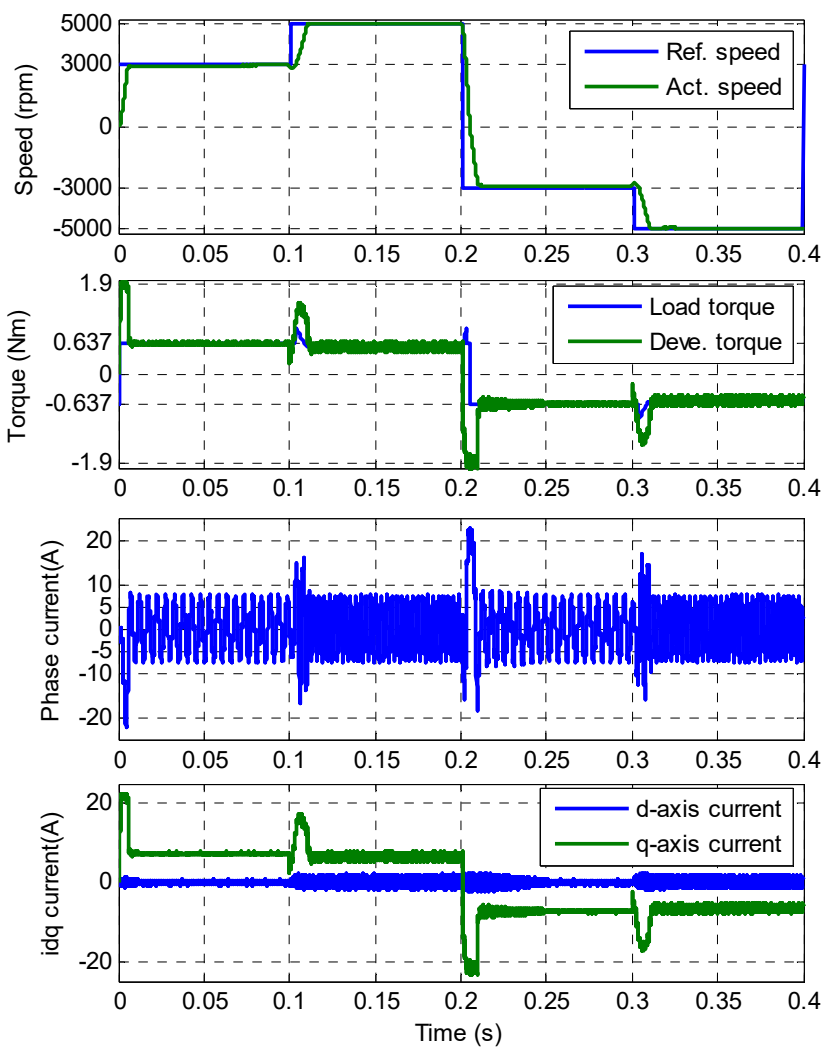

Figure 6. The dynamic performance of the PMSM side without modulated FCS-MPC. From top to bottom: reference and motor speeds, load and developed torques, phase current, and dq currents. 


\subsection{Dynamic Performance of the qZS Side}

The simulation results with the proposed modulated and unmodulated FCS-MPC for the qZSI side are shown in Figures 7 and 8, respectively. In both schemes, the reference voltage of the qZSI capacitor voltage is set based on the reference speed. It could be observed that the inductor current accurately tracks its reference in all examined operational modes, i.e., rated, maximum, and reverse modes (see Figures 7 and 8 (upper)). The capacitor voltage equals $89.25 \mathrm{~V}$ (see Figures 7 and 8 (middle)), and the peak value of the DC-link voltage becomes $127.5 \mathrm{~V}$ (see Figures 7 and 8 (bottom)).

At time $0.2 \mathrm{~s}$, the speed of the PMSM is reversed. A transient period from $0.2 \mathrm{~s}$ to $0.21 \mathrm{~s}$ occurs. During this period, the PMSM draws a high transient current to reverse its direction. Therefore, the inductor current is increased to raise up the voltage across the capacitors. At the end of this transient period, the nominal load current is drawn and hence the inductor current is decreased. Therefore, the capacitor voltage is decreased up to its steady state according to the new speed and load.
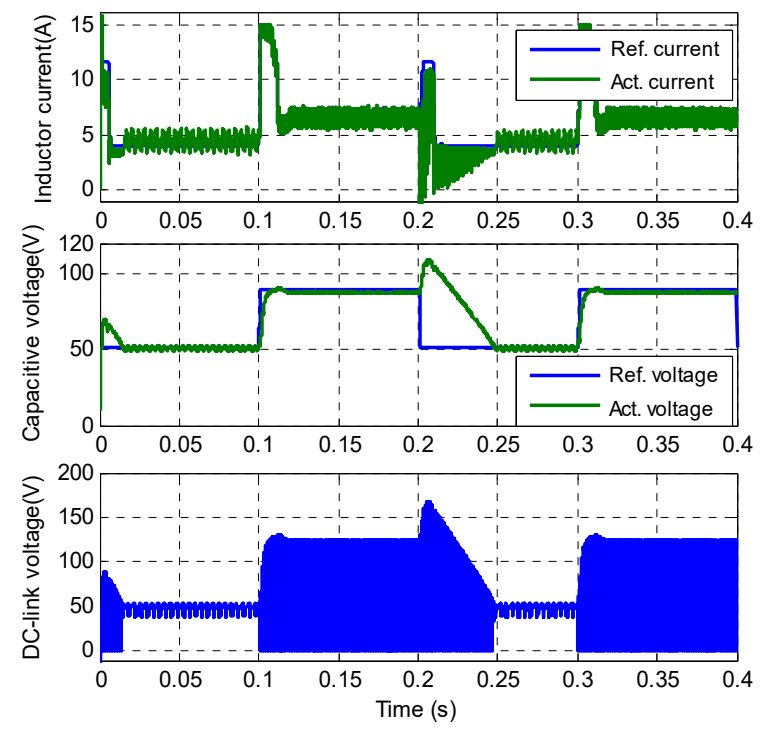

Figure 7. The dynamic performance of the qZSI side with modulated FCS-MPC. From top to bottom: inductor current, capacitor voltage, and DC-link voltage.
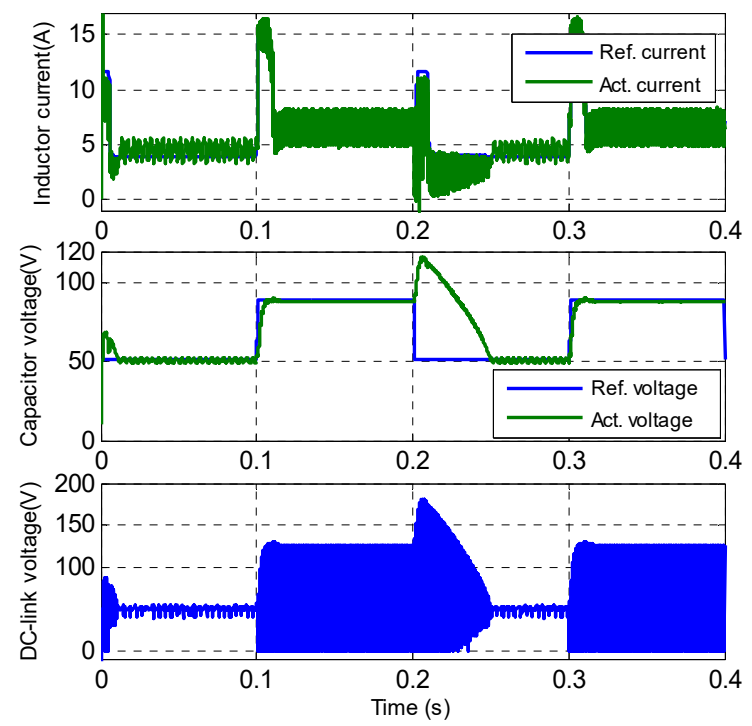

Figure 8. The dynamic performance of the qZSI side without modulated FCS-MPC. From top to bottom: inductor current, capacitor voltage, and DC-link voltage. 


\subsection{Control Variables}

Figures 9 and 10 show the control variables with M-MPC and the unmodulated MPC, respectively. Below the base speed, in forward and reverse directions, the optimal vector is selected between V2:V7; while the zero vector V1 is not used in the calculations, and no ST state (V8) is needed. In this case, there is no need to calculate the duty-cycle of the ST in (26), while the duty-active has been determined for minimizing only the ripple of the PMSM currents. When the speed exceeds the base value, the ST state is mandatorily needed to boost the dc-link voltage. Therefore, the ST vector V8 is applied during the time $\left(\mu_{s t} T_{s}\right)$. The level of the duty-ST depends on how the motor speed runs away from the base one. Without the modulation technique, as shown in Figure 11, the selected vectors have been applied during the whole sampling interval.

\subsection{Steady-State Performance of the PMSM Side}

The steady-state responses for $T_{s}=20 \mu$ are shown in Figures 11 and 12 for the MMPC and unmodulated MPC, respectively. The proposed M-MPC leads to a significantly lower current error than the unmodulated MPC. The shape of the phase current at the rated and maximum speeds is improved with the proposed M-MPC rather than the unmodulated MPC, as shown in Figure 11a,b and Figure 12a,b, respectively. The ripple in the inductor current is significantly decreased with the M-MPC, as depicted in Figure 11c, compared to the unmodulated MPC in Figure 12c, whereas the ripple in the capacitor voltage is slightly decreased with the M-MPC, as depicted in Figure 11d, compared to the unmodulated MPC in Figure 12d.
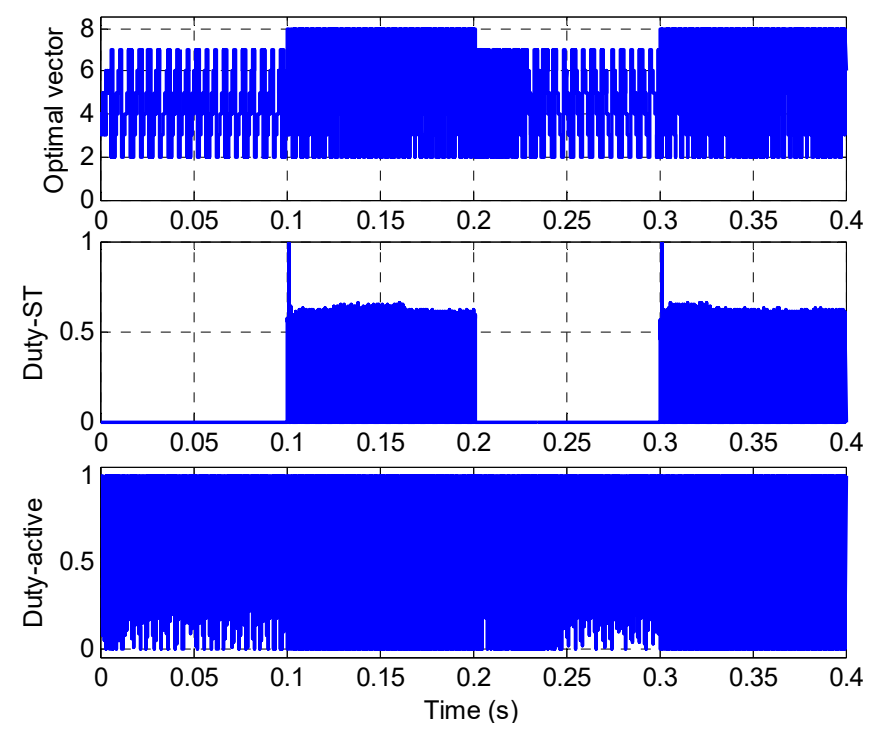

Figure 9. Control signals with the modulated FCS-MPC. From top to bottom: optimum voltage vector, optimal duty at shoot-through state, and optimal duty at active state.

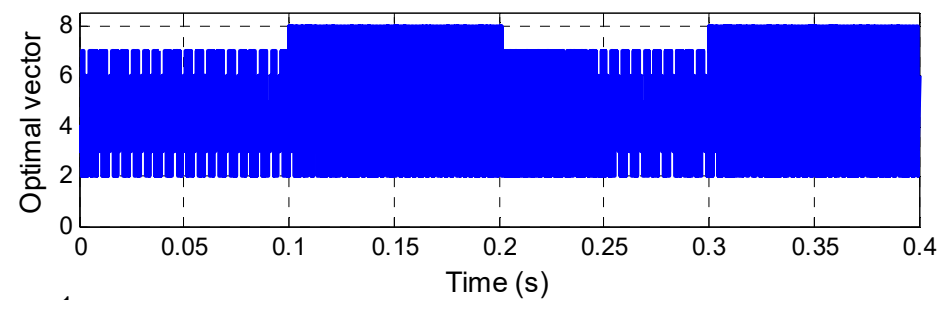

Figure 10. Optimal switching vector with the unmodulated FCS-MPC. 


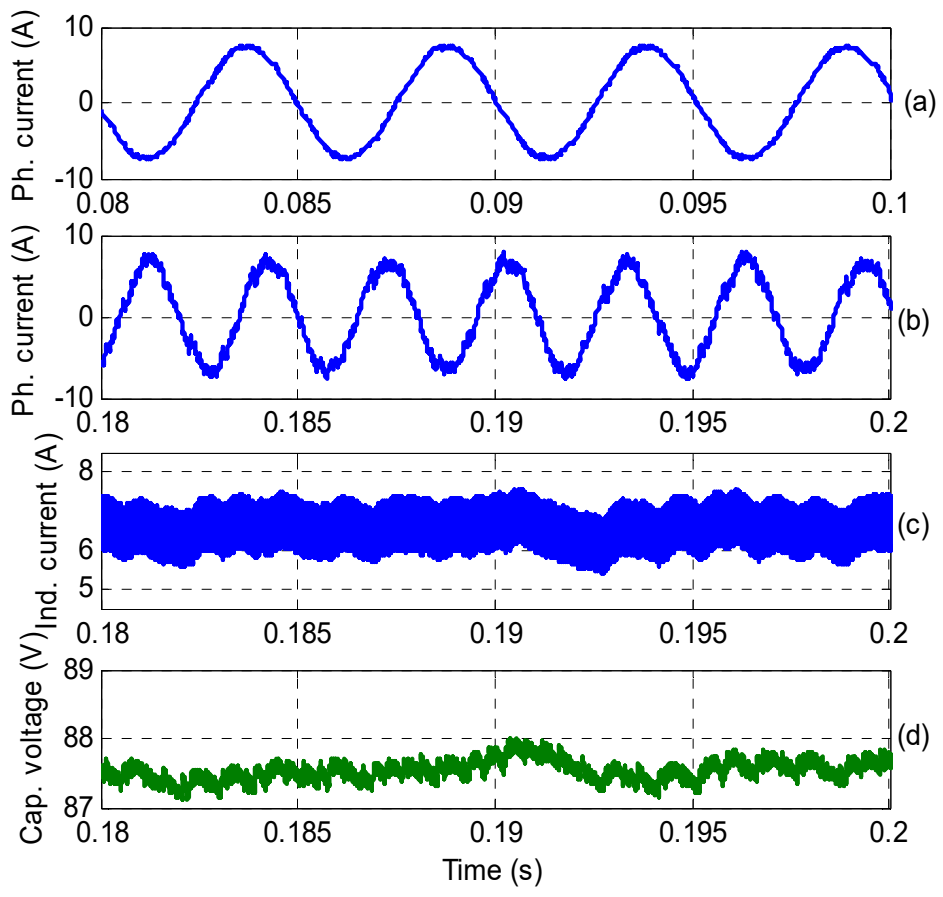

Figure 11. Steady-state performance of the modulated MPC at a sampling time of $20 \mu \mathrm{s}$ : (a) phase current below the base speed, (b) phase current above the base speed, (c) inductor current in boosting mode, and (d) capacitor voltage above the base speed.
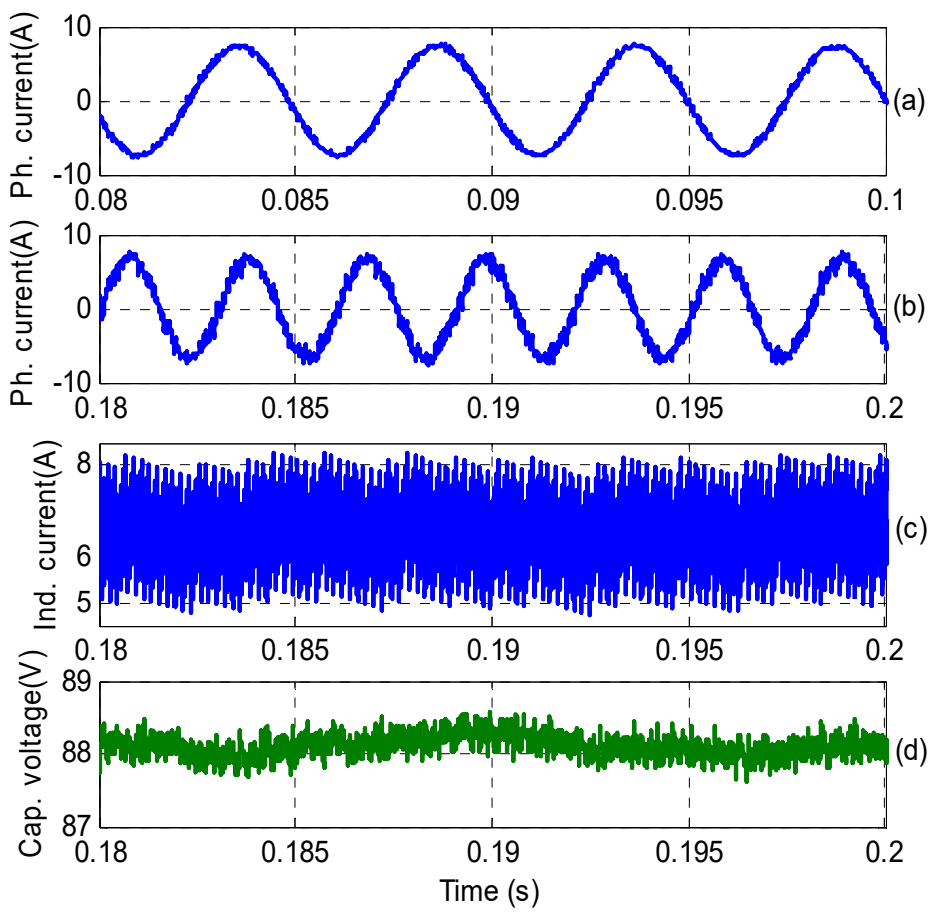

Figure 12. Steady-state performance of the unmodulated MPC at a sampling time of $20 \mu \mathrm{s}:$ (a) phasecurrent below the base speed, (b) phase-current above the base speed, (c) inductor current in boosting mode, and (d) capacitor voltage above the base speed.

The performance of the proposed MFCS-MPC is also tested at a higher sampling time, i.e., at $40 \mu \mathrm{s}$, as shown in Figure 13. From the results, the modulated algorithm guarantees a good performance of the converter and the PMSM. The performance of the control objectives is not very different compared to the modulated MPC at $20 \mu \mathrm{s}$. A low sampling time with modulation decreases the inductor current ripples. 

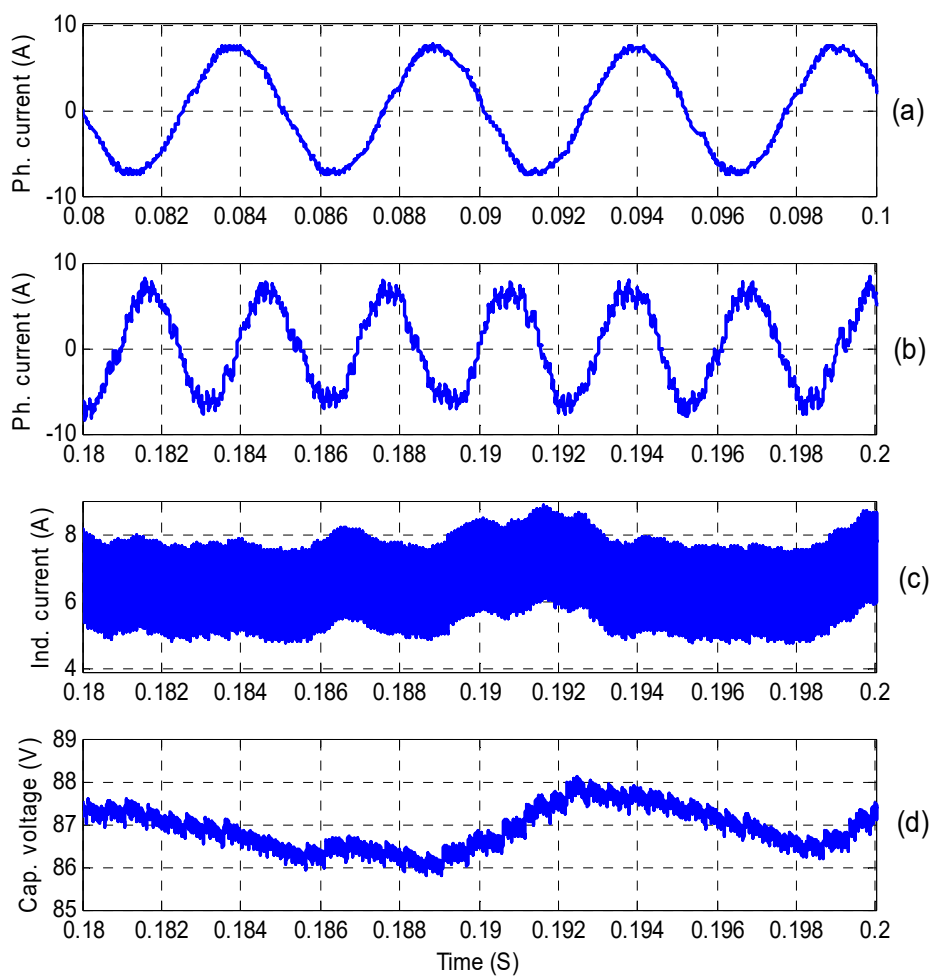

Figure 13. Steady-state performance of the modulated MPC at $40 \mu \mathrm{s}$ : (a) phase current below the base speed, (b) phase current above the base speed, (c) inductor current in boosting mode, and (d) capacitor voltage above the base speed.

\subsection{Steady-State Performance of the qZSI Side}

The optimized vector, with the traditional MPC algorithm, is applied during the entire sampling time, as shown in Figure 14. The same procedure is applied in the next sampling intervals. One vector occupies the entire the sampling interval, and there are no duty-ST and duty-active. With the proposed MPC algorithm, the optimal vector is only applied during a defined time, which has been calculated in each sampling interval, aiming to minimize the ripple in the controlled variables as derived in (26), (33), and (35). In Figure 15, in each sampling interval, there will be two possibilities for the number of vectors according to the calculated optimal times:

One vector in the sampling period: this case occurs when the duty-ST/duty-active is larger than one; then, the proposed MPC algorithm applies only the optimized vector during the entire sampling interval (V3, as shown in the region with the red outlines in Figure 15a). The possibility of this case may be higher with the active vectors, as the duty-ST is usually lower than the maximum limit at one (i.e., in the range from 0 to 0.6 in Figure 15b).

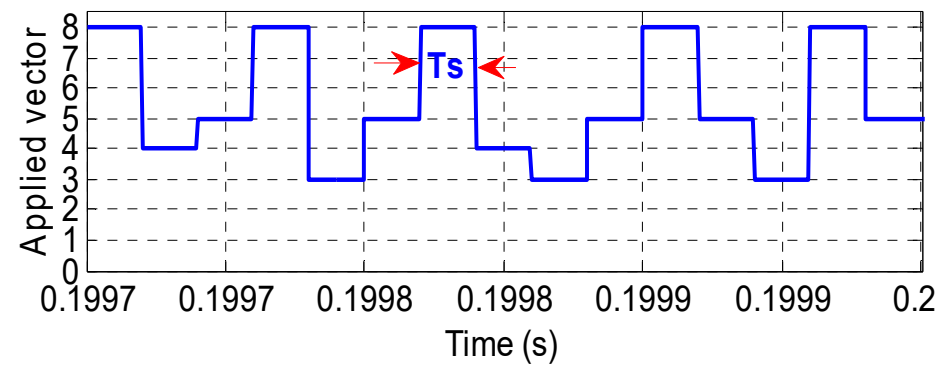

Figure 14. Steady-state performance of qZSI during $0.0003 \mathrm{~s}$ in boosting mode without modulated MPC at $20 \mu$ s, with 15 vectors transitions. 


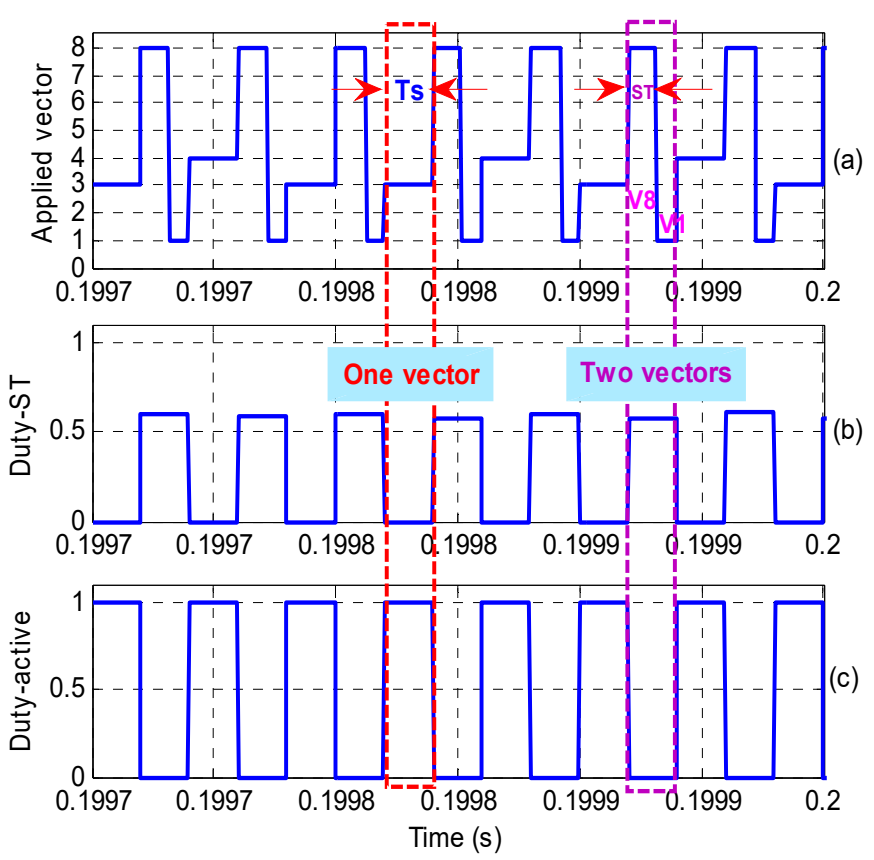

Figure 15. Steady-state performance of qZSI with modulated MPC with 22 vectors transitions during $0.0003 \mathrm{~s}$ in boosting mode at $20 \mu \mathrm{s}$ : (a) optimal voltage vector in boosting mode, (b) duty in the shoot-through state, and (c) duty in the active state.

Two vectors in the sampling interval: it is shown in the region with the purple outlines in Figure 15. It happens when the duty-ST/duty-active is less than the maximum limit at one. In the remaining part of the sampling interval (i.e., 1- Duty-ST/Duty-active), the null vector is applied to the inverter switches (V1). Moreover, as depicted in Figure 15a, it can be noticed that the optimal vector is transmitted between the six active vectors (V2:V7) and the ST vector (V8). Moreover, it is shown in Figure 15b,c that the duty-ST and the duty-active are complementary, i.e., when the duty-ST equals one, the duty-active equals zero, and vice versa.

The proposed and conventional MPC have different optimal vectors at the same time instant. For example, at instant $0.1998 \mathrm{~s}$, the optimal vector of the proposed algorithm is V8, while the conventional algorithm is V5, as depicted in Figures 14 and 15a, respectively. Furthermore, at this instant, the conventional algorithm applies only the vector V5 during the whole sampling interval $(100 \%)$, while with the proposed algorithm, the optimal vector V8 occupies only approximately $59 \%$ of the sampling interval, and the remaining part of $41 \%$ is occupied by the zero vector. Interrupting the vector V8 with the vector V1 (null vector) prevents the inductor current from increasing, and thus the ripple can be minimized.

As shown in [27], the conventional FCS-MPC provides a lower computational burden, whereas the FCS-MPC with an optimal time interval is the highest calculation time consumer. Here, the numbers of switching transitions during a certain period are shown in Figures 14 and 15. It is also seen that the proposed method increases the number of switching transitions ( 22 transitions during $0.0003 \mathrm{~s}$ ) in comparison with the conventional method (15 transitions during $0.0003 \mathrm{~s}$ ) because, in this case, the duty of shoot-through is less than one. Therefore, the sampling interval of the shoot-through includes two vectors to minimize the inductor current. As a result, the switching frequency of the inverter increases with the proposed technique. However, with the unmodulated MPC, increasing the switching frequency requires decreasing the sampling time. This is considered a limitation to the conventional algorithm, as operating at a low sampling interval requires a high-cost powerful digital platform (i.e., FPGA). Moreover, with the unmodulated MPC, the computational burden will increase intensively, as all calculations will be doubled in 
case of decreasing the sampling interval to double the switching frequency. However, with the proposed algorithm, the computational burden will be almost the same.

With the unmodulated MPC, shown in Figure 14, the sampling time is $20 \mu \mathrm{s}$ and the switching frequency is $50 \mathrm{kHz}$, while with the modulated MPC, shown in Figure 15, the sampling time is $20 \mu \mathrm{s}$ and the switching frequency is $73.33 \mathrm{kHz}$. To compare the steady-state performance of the studied MPC schemes under the same average switching frequency, the applied voltage vector is recorded at $13.6 \mu$ s with the unmodulated MPC, as shown in Figure 16. Comparing this value to the results in Figure 15a, it can be noted that same shoot-through states occur in the same time period; then, the THD for the PMSM currents is the same for the studied system. Moreover, the inductor current ripple and the capacitor voltage will be identical in both algorithms.

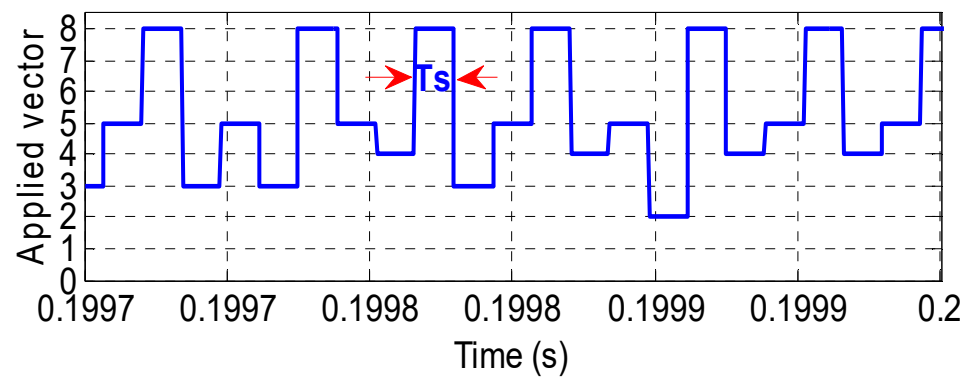

Figure 16. Steady-state performance of qZSI during $0.0003 \mathrm{~s}$ in boosting mode without modulated MPC at sampling time $13.6 \mu \mathrm{s}$, with 22 vectors transitions.

Table 4 summarizes the results acquired for the steady-state simulations when the PMSM is operating at the maximum and rated speeds of 5000 and $3000 \mathrm{rpm}$, respectively. The current error is defined as the absolute band between the peak limit and the lower boundary of the wave for the measured wave related to its reference. It could be noted that the proposed modulated MPC reduces the ripples of the control variables compared to the unmodulated MPC along with the whole speed range.

Table 4. Comparison in state-variable ripples with modulated and unmodulated FCS-MPC.

\begin{tabular}{ccccc}
\hline Speed & Variables & FCS-MPC & M-FCS-MPC & Enhanced Percentage (\%) \\
\hline \multirow{3}{*}{$3000 \mathrm{rpm}$} & $I_{L 1}(A)$ & 2.3 & 2.2 & 4.3 \\
& $V_{c 1}(V)$ & 3.1 & 2.75 & 11.3 \\
& $I_{s d}(A)$ & 1.4 & 0.8 & 42.8 \\
& $I_{s q}(A)$ & 0.8 & 0.4 & 50 \\
\hline \multirow{5}{*}{$5000 \mathrm{rpm}$} & $I_{L 1}(A)$ & 3.3 & 2.2 & 51.5 \\
& $V_{c 1}(V)$ & 0.8 & 2.75 & 40.5 \\
& $I_{s d}(A)$ & 3.7 & 0.8 & 23 \\
\hline
\end{tabular}

It is common for the predictive control to result in a variable switching frequency. The average switching frequency with the modulated and unmodulated FCS-MPC is compared in Figure 17 for different sampling intervals. The simulation results are obtained at the boosting mode where the calculations of the optimal duty-cycle are required with the proposed algorithm, while during the buck mode, both algorithms will have the same execution time. Based on the results, the switching frequency of the proposed algorithm is higher, as the sampling interval mostly includes two vectors instead of one (as in the conventional algorithm). Therefore, the proposed algorithm has a slightly higher execution time to find the optimal duty-cycle during the boost mode. However, this small time difference is not considered a big issue, as the modern digital controller can operate at a higher execution speed. 


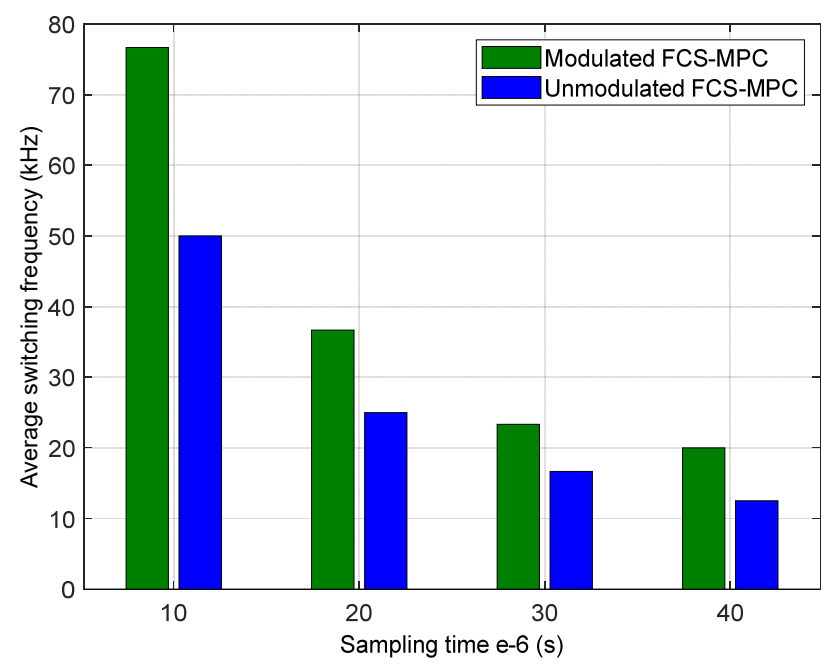

Figure 17. Comparison between the average switching frequency (in $\mathrm{kHz}$ ) with modulated and unmodulated FCS-MPC for PMSM driven by qZSI.

\subsection{Total Harmonic Distortion (THD)}

To visually compare and analyze the performance of the current under the control strategy, it is necessary to investigate the total harmonic distortion (THD) of the phase current. The THD analysis of the phase current of the PMSM at rated and maximum speeds and rated torque operating conditions is shown in Figure 18a-d for the M-MPC and the unmodulated MPC, respectively. The FFT analyzer has been performed to one cycle of the phase current starting from $0.08 \mathrm{~s}$ at $3000 \mathrm{rpm}$ in Figure $11 \mathrm{a}$ and at $0.18 \mathrm{~s}$ at $5000 \mathrm{rpm}$ in Figure 11b. The figures illustrate that the M-MPC results in a significantly lower THD than the conventional MPC in both conditions of rated speed and maximum speed. From the presented analysis, it can be concluded that the proposed modulated-MPC has a superior tracking capability for all control variables.

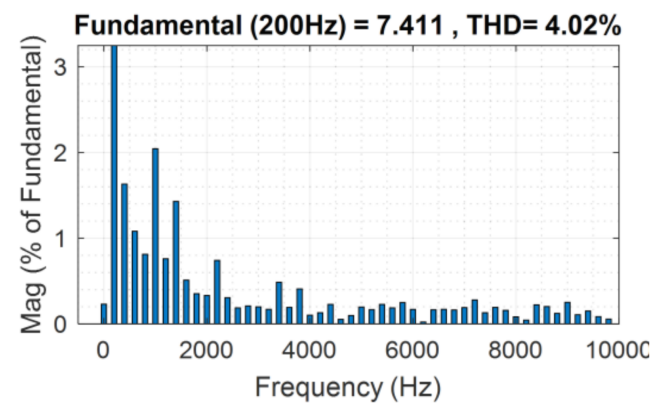

(a)

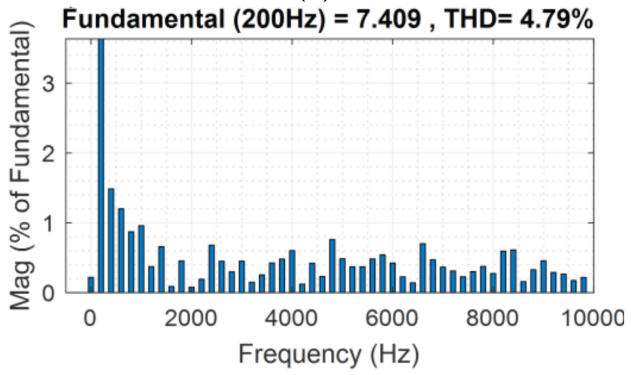

(c)

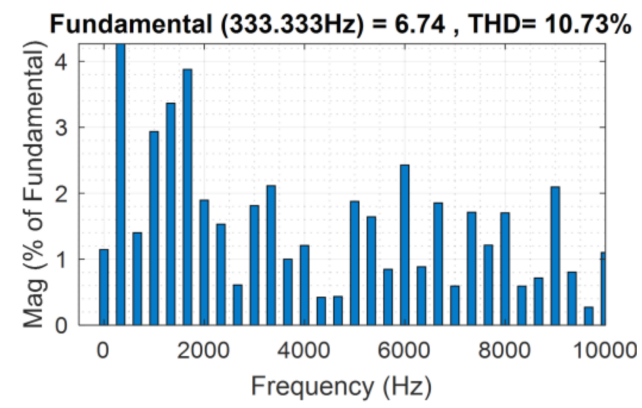

(b)

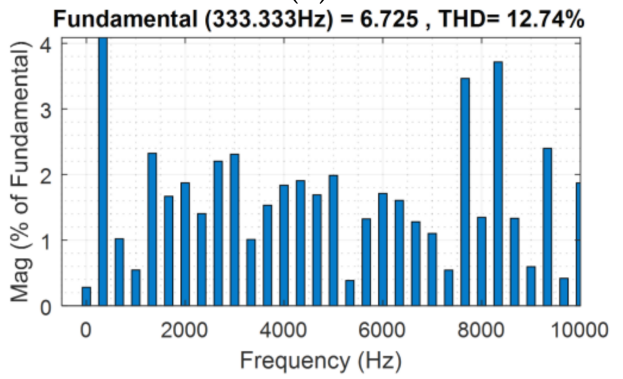

(d)

Figure 18. THD of the stator phase-current with the modulated and conventional FCS-MPC: (a) M-MPC at a rated speed of $3000 \mathrm{rpm}$, (b) M-MPC at a maximum speed of $5000 \mathrm{rpm}$, (c) FCS-MPC at a rated speed of $3000 \mathrm{rpm}$, and (d) FCS-MPC at a maximum speed of $5000 \mathrm{rpm}$. 


\section{Conclusions}

This paper has proposed a modulated FCS-MPC method to reduce the current and voltage ripples of the qZSI as well as to control the current of the PMSM in its whole speed range without excessive load operation. The following points could be concluded from this work:

- The proposed M-MPC divides the sampling interval into two times, i.e., the optimal voltage vector and the null voltage vector.

- The PMSM can run with a speed beyond the base speed without the need to apply the FWC to avoid a high drawn phase current.

- The ripples of the phase current either in buck mode or in boost mode have been reduced with the proposed M-MPC by 42.8 and $40.5 \%$, respectively, in the d-axis direction; and by 50 and $23 \%$, respectively, for the q-axis component.

- The peak-to-peak ripples of the inductor current have been decreased in the buck and boost modes by 4.3 and $51.5 \%$, respectively.

- The peak-to-peak ripples of the capacitor voltage have been decreased in the buck and boost modes by 11.3 and $50 \%$, respectively

- The THD factor for phase current is decreased by 16 and $15.8 \%$ with the modulated MPC at rated and maximum speeds, respectively.

Hence, with the proposed M-MPC, the performances of qZSI and the PMSM have been improved over a large speed profile. The proposed strategy could therefore be applied in industrial applications with MPC for minimizing the ripples and matching the reference variables. However, the suggested algorithm could suffer from some limitations. The higher switching frequency is the drawback of the suggested algorithm, especially at the low sampling time. Hence, it limits the operation of both the processor and the power switches. However, the advances in those tools guarantee the solution to this problem. As is known, the MPC is a control algorithm that is sensitive to parameter variations, i.e., parameters of PMSM and of qZSI. The modulation interval of the proposed algorithm is expected to be modified to yield a good performance. This point will be researched in detail in the future.

Author Contributions: Conceptualization, A.A.A., A.B. and H.H.A.; methodology, A.A.A., A.B. and M.A.M.; software, A.A.A. and A.B.; validation, A.A.A. and A.B.; formal analysis, A.A.A., A.B., P.S. and M.A.M.; investigation, A.A.A., A.B. and M.A.M.; resources, A.A.A., A.B. and P.S.; data curation, A.A.A., A.B. and M.A.M.; writing-original draft preparation, A.A.A. and A.B.; writing-review and editing, A.A.A., A.B., H.H.A. and M.A.M.; visualization, A.A.A. and A.B.; supervision, A.A.A., H.H.A. and P.S.; project administration, A.A.A., H.H.A. and P.S.; funding acquisition, A.A.A., H.H.A. and P.S. All authors have read and agreed to the published version of the manuscript.

Funding: This research received no external funding.

Data Availability Statement: The data presented in this study are available upon request from the first author (A.A.A.).

Conflicts of Interest: The authors declare no conflict of interest.

\section{References}

1. Siwakoti, Y.P.; Peng, F.Z.; Blaabjerge, F.; Loh, P.C.; Town, G.E.; Yang, S. Impedance-source networks for electric power conversion part II: A topological review. IEEE Trans. Power Electron. 2015, 30, 699-716.

2. Siwakoti, Y.P.; Peng, F.Z.; Blaabjerge, F.; Loh, P.C.; Town, G.E.; Yang, S. Impedance-source networks for electric power conversion part II: Review of control and modulation techniques. IEEE Trans. Power Electron. 2015, 30, 1887-1906.

3. Bakeer, A.; Ismeil, M.A.; Orabi, M. A modified two-switched inductors quasi z-source inverter. In Proceedings of the IEEE Applied Power Electronics Conference and Exposition (APEC), Charlotte, NC, USA, 15-19 March 2015; pp. $1693-1699$.

4. Xiao, S.; Gu, X.; Wang, Z.; Shi, T.; Xia, C. A novel variable dc-link voltage control method for PMSM driven by a quasi-z-source inverter. IEEE Trans. Power Electron. 2020, 35, 3878-3890.

5. Xiao, S.; Shi, T.; Li, X.; Wang, Z.; Xia, C. Single-current-sensor control for PMSM driven by quasi-z-source inverter. IEEE Trans. Power Electron. 2019, 34, 7013-7024. 
6. Battiston, A.; Miliani, E.; Pierfederici, S.; Meibody, F. Efficiency improvement of a quasi-z-source inverter-fed permanent-magnet synchronous machine-based electric vehicle. IEEE Trans. Transp. Electrif. 2016, 2, 14-23.

7. Bakeer, A.; Ahmed, A.A. Performance evaluation of PMSM based on model predictive control with field weakening operation and bidirectional quasi z-source inverter. In Proceedings of the 19th International Middle East Power Systems Conference, Cairo, Egypt, 19-21 December 2017; pp. 741-746.

8. Ahmed, A.A.; Qunato, A.; Li, S. DSP-based implementation of permanent magnet synchronous motor drives for EV/HEV applications. In Proceedings of the 16th International Middle East Power Systems Conference, Cairo, Egypt, 23-25 December 2014.

9. Pan, C.T.; Liaw, J.H. A robust field-weakening control strategy for surface-mounted permanent-magnet motor drives. IEEE Trans. Energy Convers. 2005, 20, 701-709.

10. Ahmed, A.A. Fast-speed drives for permanent magnet synchronous motor based on model predictive control. In Proceedings of the 2015 IEEE Vehicle Power and Propulsion Conference (VPPC), Montréal, QC, Canada, 19-22 October 2015.

11. Ayad, A.; Karamanakos, P.; Kennel, R.; Rodríguez, J. Direct model predictive control of bidirectional quasi-z-source inverters fed PMSM drives. In Proceedings of the 11th IEEE International Conference in Compatibility, Power Electronics and Power Engineering, Cadiz, Spain, 4-6 April 2017; pp. 671-676.

12. Magdy, G.; Bakeer, A.; Shabib, G.; Elbaset, A.A.; Mitani, Y. Decentralized model predictive control strategy of a realistic multi power system automatic generation control. In Proceedings of the 19th International Middle East Power Systems Conference, Cairo, Egypt, 19-21 December 2017; pp. 190-196.

13. Dong, K.; Shi, T.; Xiao, S.; Li, X.; Xia, C. Finite set model predictive control method for quasi-Z source inverter-permanent magnet synchronous motor drive system. IET Electric. Power Appl. 2019, 13, 302-309.

14. Bakeer, A.; Ismeil, M.A.; Orabi, M. A powerful finite control set-model predictive control algorithm for quasi z-source inverter. IEEE Trans. Ind. Inform. 2016, 12, 1371-1379.

15. Ellabban, O.; Abu-Rub, H.; Rodriguez, J. Predictive torque control of an induction motor fed by a bidirectional quasi z-source inverter. In Proceedings of the 39th IEEE Annual Conference of IECON, Vienna, Austria, 10-13 November 2013; pp. 5854-5859.

16. Davari, S.A.; Khaburi, D.A. Using predictive control and q-ZSI to drive an induction motor supplied by a PV generator. In Proceedings of the 5th Power Electronics, Drive Systems and Technologies Conference, Tehran, Iran, 5-6 February 2014; pp. 61-65.

17. Chen, W.; Zeng, S.; Zhang, G.; Shi, T.; Xia, C. Modified double vectors model predictive torque control of permanent magnet synchronous motor. IEEE Trans. Power Electron. 2019, 34, 11419-11428.

18. Mahmoudi, H.; Aleenejad, M.; Ahmadi, R. A new multiobjective modulated model predictive control method with adaptive objective prioritization. IEEE Trans. Ind. Appl. 2017, 53, 1188-1199.

19. Hamid, M.; Mohsen, A.; Reza, A. Modulated model predictive control for a z-source based permanent magnet synchronous motor drive system. IEEE Trans. Ind. Electron. 2017, 65, 8307-8319.

20. Mahmoudi, H.; Aleenejad, M.; Ahmadi, R. Torque ripple minimization for a permanent magnet synchronous motor using a modified quasi-z-source inverter. IEEE Trans. Power Electron. 2019, 34, 3819-3830.

21. Jinpeng, Y.; Lin, Z.; Haisheng, Y.; Chong, L. Barrier Lyapunov functions-based command filtered output feedback control for full-state constrained nonlinear systems. Automatica 2019, 105, 71-79.

22. Cheng, F.; Qing-Guo, W.; Jinpeng, Y.; Chong, L. Neural network-based finite-time command filtering control for switched nonlinear systems with backlash-like hysteresis. IEEE Trans. Neural Netw. Learn. Syst. 2020, 32, 3268-3273.

23. Guozeng, C.; Jinpeng, Y.; Qing-Guo, W. Finite-time adaptive fuzzy control for MIMO nonlinear systems with input saturation via improved command-filtered backstepping. IEEE Trans. Syst. Man Cybern. Syst. 2020.

24. Jinpeng, Y.; Peng, S.; Jiapeng, L.; Chong, L. Neuroadaptive finite-time control for nonlinear MIMO systems with input constraint. IEEE Trans. Cybernetics 2020, 1-8.

25. Yuhao, X.; Yuyao, H.; Shengchao, L. Logical operation-based model predictive control for quasi-z-source inverter without weighting factor. IEEE J. Emerg. Sel. Top. Power Electron. 2021, 9, 1039-1051.

26. Monfared, K.K.; Miremad, A.; Iman-Eini, H.; Neyshabouri, Y. Finite control set model predictive control for static synchronous compensator based on hybrid cascaded H-bridge and neutral point clamped multilevel inverter. Int. Trans. Electr. Energ. Syst. 2021, 31, e12745.

27. Ahmed, A.A.; Koh, B.K.; Lee, Y.I. A comparison of finite control set and continuous control set model predictive control schemes for speed control of induction motors. IEEE Trans. Ind. Inform. 2018, 14, 1334-1346. 